\title{
How Could Policies Facilitate Digital Transformation of Innovation Ecosystem: A Multiagent Model
}

\author{
Wei Yang $(\mathbb{D}$, Jian Liu, Lingfei Li $(\mathbb{D}$, Qing Zhou $\mathbb{D}$, and Lixia Ji \\ Management School, Hangzhou Dianzi University, Hangzhou 310018, China \\ Correspondence should be addressed to Qing Zhou; zhq7980@126.com
}

Received 6 August 2020; Revised 14 December 2020; Accepted 1 January 2021; Published 13 January 2021

Academic Editor: Yi Su

Copyright (c) 2021 Wei Yang et al. This is an open access article distributed under the Creative Commons Attribution License, which permits unrestricted use, distribution, and reproduction in any medium, provided the original work is properly cited.

\begin{abstract}
The digital transformation of the innovation ecosystem is not only an inevitable direction of innovation activities in the era of digital economy but also a highly complex and uncertain process. The way to facilitate transformation with policies has become a topic of common concern of academia and policymakers. This paper builds a multiagent model and studies the impacts of supplyside policies, demand-side policies, and environmental policies on enterprises' transformation willingness, digital level, and income level as well as the proportion of enterprises that carry out transformation in the whole innovation ecosystem and innovation network structure by numerical experiments. According to research findings, supply-side policies play the biggest role in the facilitation of transformation, demand-side policies are second important to them, and environmental policies have comparatively weak impacts.
\end{abstract}

\section{Introduction}

The rapid development of digital technologies has reshaped human society and given rise to the trend of digital transformation. In the field of business, digital technologies have not only generated profound impacts on contents, approaches, and organizational forms of innovation activities but also attracted extensive attention from academia and industry. Existing researches commonly believed that the application of digital technologies benefited the optimization of enterprises' innovation process and improved enterprises' innovative performance [1-3]. Accompanied with the emergence of open innovation in recent years, scholars also discussed the impacts of enterprises' IT investments on availability of external resources and performance of open innovations [4-6] and found the nonlinear interactions between those two. However, existing researches were still mainly based on the digital transformation of individual enterprises and rarely discussed the digital transformation of innovation systems as a whole.

Meanwhile, researches on innovation ecosystem transformation failures also received attention from academia in recent years [7], particularly the way to avoid transformation failure through effective policy means [8]. However, among such researches, the transformation of innovation ecosystem was neither placed under more scenario-based discussions nor specific to digital transformation.

Based on the abovementioned information, the research topic of this paper is whether and how could policies facilitate the digital transformation of the innovation ecosystem? This paper uses the concept of innovation ecosystem to depict interactions and influence relations among enterprises' innovation activities [9] and uses the digital transformation to reflect innovation ecosystem's agents' adoption of information technology as well as changes in innovation activities incurred thereby [10]. Considering the innovation ecosystem is a typical complex system [11] and digital transformation is a "bottom-up" evolution process, an agent-based model is an appropriate approach to study such complicated issues [12]. To be specific, this paper builds a multiagent model for the digital transformation of innovation ecosystem, introduces supply-side, demand-side, and environmental policies, and identifies the impacts of different types of policies on the digital transformation of innovation ecosystem through computational experiments. 


\section{Theoretical Background}

2.1. Digital Transformation of Innovation Ecosystem. According to the latest research by Granstrand and Holgersson [13], this paper defines the innovation ecosystem as "evolving set of actors, activities, artifacts, institutions, and relations, including complementary and substitute relations that are important for the innovative performance of an actor or a population of actors." In essence, the innovation ecosystem is an organization system of integration and coordination of innovation resources. Furthermore, knowledge resources spillover, diffusion and transfer among different innovation agents $[14,15]$, and the corresponding absorptive capacity have important influence on innovation performance [16]. The innovation ecosystem can be divided into different levels such as enterprise, region, and industry, which play a positive role in innovation performance and sustainable development [17]. From the perspective of complex system, different levels of innovation ecosystem showed "bottom-top" and "micro-macro" ecological agglomeration relations [18].

The digital transformation of innovation ecosystem takes the digital transformation of enterprises and other innovation agents as microfoundation first. To enterprises, digital transformation refers to major changes in strategy, organizational structure, product operation, business model, and other aspects brought by digital technologies, which are characterized by their integration, span, and strong environmental dependency [19]. Meanwhile, the system attribute of innovation ecosystem means digital transformation changes in whole system structure, function, and operating mechanism arising out of correlated microtransformation activities instead of the simple accumulation of digital transformation activities of individual enterprises. To be specific, such changes are reflected in the two aspects of innovation activities and innovation organization mode in a centralized manner.

On the one hand, digital innovation has become a dominant innovation activity. Digital innovation refers to the production of new products or services, development of new processes, or creation of new business models through digital technologies, which are featured by significant characteristics of ambiguous boundaries, flexible and changeable innovation agents, as well as intertwined innovation process and innovation results [20]. Digital innovation can be also taken as a "new combination" of digital technologies with enterprises' existing products, processes, and business models [21], and this is exactly the connotation and inevitable path of digital transformation [22].

On the other hand, innovation organization mode has shown characteristics of online and offline integration. Online initiatives are dominated by an allocation of information, coded knowledge, data, and other resources, while offline initiatives are dominated by tacit knowledge exchange, production, and transportation of physical resources and products as well as other activities. This is not only the result of changes in communication methods and improvement of efficiency brought by digital technologies but also the result of increasing distribution and democratization of innovation agents $[23,24]$. Online and offline integration is mainly reflected by the increasingly prominent role of digital platforms in the innovation ecosystem. From the perspective of technology, digital platform refers to extensible codebase that can embed third-party modules. From the perspective of the sociotechnical system, digital platform refers to the set of technical elements, organizational processes, and standards [22]. The digital platform has provided a space for online and offline interactions of innovation agents, and restructuring of innovation organization mode by the digital platform has become a significant characteristic of the digital transformation of an industry's innovation ecosystem.

2.2. Impacts of Policies on Digital Transformation of Innovation Ecosystem. The digital transformation of innovation ecosystem has high complexity and uncertainty, which led to transformation failures. To cope with complexity and uncertainty in transformation, policymakers would actively develop and implement a series of policy tools to facilitate transformation. Based on research on the classification of policy tools conducted by Huang and others [25] and analysis on functions of the innovation ecosystem carried out by Hekkert et al. [26], this paper divides policy tools to facilitate transformation into three categories.

The first category is the supply-side policies. Such policies mainly drive the transformation through increasing supply of technology, fund, information, and other key elements required. Consumption of different resources constitutes the main source of transformation cost, so the main function of supply-end policies is the reduction of transformation cost. The second category is the demand-side policies. Such policies mainly drive transformation through increasing market demand for transformation, such as government purchase services and adjustment of market entrance criteria. The demand-side policies can play comprehensive roles, and they can affect individuals' willingness to transform by means of reducing uncertainty and changing market structure. The third category is the environmental policies. Such policies mainly drive transformation through improving the economic, social, and institutional environments that are required by transformation. Environmental factors have indirect and common impacts on transformation activities, which can create a favorable atmosphere or "field" for transformation as a whole. Such an atmosphere can cause isomorphic pressure on individuals and thus facilitate individuals' willingness to transform.

The three aforementioned policies will eventually affect the digital transformation of innovation ecosystem from micro- and macro perspectives. From a microperspective, the first impact is individual enterprises' willingness to transform. As mentioned above, in the case of a complex system, individuals' transformation activities constitute microfoundation of the whole system's transformation, and individuals' willingness to transform is the premise of their implementation of transformation. The second impact is enterprises' digital levels, which reflect changes in the technical dimension brought by transformation to 
enterprises. The third impact is enterprises' economic benefits, which are both economic results of transformation and important motivation for enterprises to carry out transformation. From the perspective of the macrosystem, the first impact is the proportion of enterprises carrying out digital transformation in the system, while the second impact is the changes in network structure of the innovation ecosystem. Characteristics of the digital transformation of innovation ecosystem are reflected by those two impacts.

\section{Model}

Different policies will promote the digital transformation of enterprises from different aspects and increase the level of digitization of enterprises, and the level of digitization of enterprises will affect the cooperative innovation between enterprises, leading to the evolution of the innovation ecosystem. Based on this idea, this paper builds a multiagent model for the digital transformation of innovation ecosystem to study whether and how could supply-side, demandside, and environmental policies facilitate the digital transformation of innovation ecosystem. Then, we will explain our model in this paper from four aspects: agents and their attributes, the interaction between agents, the endogenous and external environment where the model is located, and the complete simulation process of the model.

3.1. Agents. This section introduces the agents involved in our model. In order to study how can policies facilitate digital transformation of innovation ecosystem, two types of agents are designed in the simulation model. One is the enterprise, which is the main body of the innovation ecosystem, and the other is IT application, which embodies the existing digital technology in the innovation ecosystem.

An enterprise may choose whether it is going to carry out digital transformation based on the existing policies and the enterprise's revenue, choose whether to conduct cooperative innovation based on the digital level in the innovation ecosystem, and then acquire a certain market share based on existing conditions. Its attributes include the enterprise's market share, net income, digital level, and cooperative relations with other enterprises. An enterprise's market share of the present period determines its current net income, the connection between an enterprise and IT application determines the enterprise's digital level, and the connection between enterprises represents their cooperative innovation.

IT application represents digital technology, it is a 10dimensional vector, and the value of each element of the vector is 0 or 1 , which indicates the state of the digital technology on that attribute. For instance, if vector of a certain digital technology is $\left[\begin{array}{llllllllll}1 & 0 & 0 & 1 & 0 & 1 & 0 & 0 & 0 & 1\end{array}\right]$, then the value of 1 for the first dimension means the state of the digital technology on the first attribute is "1."

3.2. Interactions. This section introduces the interaction between agents in our model. Interactions in the simulation models can be divided into two types, which include interactions between enterprise and IT application and interactions between enterprises.

Interactions between enterprise and IT application include an enterprise's upgrading of existing IT application as well as an enterprise's building of new IT application. An enterprise is connected with a certain IT application, which means the enterprise possesses such digital technology. The number of IT applications connected with an enterprise represents the enterprise's digital level.

Interactions between enterprises refer to cooperative innovations between enterprises, and an edge will be added to connect two enterprises if they have cooperative innovation, which will eventually form a network of cooperative innovations.

3.3. Environment. This section introduces the endogenous and external environments of the simulation model in this paper. Environment in simulation system includes the endogenous environment of enterprises and the external environment of the whole innovation ecosystem. The endogenous environment of enterprises mainly refers to different rules that affect an enterprise's decision-making process, while the external environment refers to external digital demands. That is, with the development of information technology, consumers will put forward new technical demands for products every once in a while. This external market environment prompts enterprises to upgrade digitally to obtain the digital technology, and the enterprises that have acquired this kind of digital technology can apply it to innovation activities to gain an advantage in the competition. In this paper, we assume such external digital demand is also a 10-dimensional vector, and the value of each element of the vector is 0 or 1 .

3.4. Process. In this section, we introduce the complete simulation process of the multiagent model in this paper. The model includes five stages: initialization stage, digital demand release stage, enterprise digital transformation stage, cooperative innovation stage, and market share redistribution stage. It simulates the processes of the creation of a new digital demand from the external environment, to the enterprises trying digital transformation to realize this new digital demand, launches cooperative innovation activities to form an innovation network, and finally rewrites the allocation of market share based on successful innovation activities:

(1) Initialization. Assume the market size of the whole network is MS, and there are $M$ enterprises and N IT applications in the network. The $N$ IT applications are connected with $M$ enterprises randomly. Considering that the real market environment usually shows a long tail distribution, this article assumes that, among the $M$ enterprises, few of them have relatively large market share, and most of them have comparatively small market share.

(2) The external environment releases a digital demand at a certain interval. 
(3) Stage of digital transformation. To meet digital demands of the external environment, enterprise will consider carrying out digital transformation. Enterprise's willingness to carry out digital transformation $P$ is affected by expected cost, expected net income, and policies. Among them, the expected cost is the decisive condition that affects whether an enterprise will choose digital transformation. It is affected by technology gaps and unit costs of transformation. Expected net income is an important factor in promoting enterprises to choose digital transformation, and it is affected by the average net income of related companies. The three kinds of policies affect the enterprise's willingness to digital transformation in different ways. Supply-side policies affect the willingness of enterprises to transform by affecting the unit cost of digital transformation, demand-side policies trigger the willingness of enterprises to transform by increasing market demand, and environmental policies encourage enterprises to carry out digital transformation through the pressure of cooperative enterprises. The following article discusses it in detail:

Expected cost. Enterprise decides whether it should consider digital transformation based on expected digital transformation cost, and the enterprise will abandon digital transformation if expected cost is greater than the enterprise's present capital, and transformation willingness $P=0$.

The expected cost of digital transformation is related to the effort required by the enterprise for the transformation. Since this article uses a ten-dimensional vector to represent the IT application and the digital requirements of the enterprise itself, each dimension of the vector represents the capabilities required to realize the digital technology; thus, expected digital transformation cost can be estimated by the similarity between vectors of the enterprise's own IT application and digital demand. Compare the minimum number of mismatches between digital demand vector and the enterprise's IT application vector, that is, the number of elements that are 1 in the digital demand vector but are 0 in the existing IT application; the enterprise will upgrade existing IT application with an expected cost of $\mathrm{Cu} * k$ if the minimum number of mismatches $k$ is not greater than $T_{k}$, and the enterprise will build new IT application with the expect cost of $\mathrm{Cb} * k$ if the minimum number of mismatches $k$ is greater than $T_{k}$, among which $\mathrm{Cu}$ is the unit cost for the upgrading of existing IT application and $\mathrm{Cb}$ is the unit cost for the building of a new IT application. For instance, if $T_{k}=3$, an enterprise possesses a certain digital technology $\left[\begin{array}{llllllllll}0 & 0 & 0 & 1 & 0 & 0 & 0 & 0 & 1 & 0\end{array}\right]$; digital demand released by the market at present is $\left[\begin{array}{llllllllll}0 & 0 & 0 & 1 & 1 & 0 & 0 & 0 & 1 & 0\end{array}\right]$, then number of mismatches between existing digital technology and digital demand is 1 , which is less than the threshold $T_{k}$. Hence, the expected cost of the enterprise's digital transformation is $\mathrm{Cu} \times 1$.

Expected net income. Enterprise decides whether it should carry out digital transformation based on expected net income of digital transformation, the enterprise will abandon digital transformation if expected net income is less than the enterprise's transformation cost, and transformation willingness $P=0$.

An enterprise's expected income is estimated by the average net income of enterprises one level higher than it in the digital level at the current stage. If there is no prior knowledge, the enterprise will consider digital transformation as long as expected digital transformation cost is less than present capital.

Effects of policies. Enterprise's willingness to carry out digital transformation $P$ is the result of the three parts of supply-side policies, demand-side policies, and environmental policies.

The main function of supply-side policies is a reduction of transformation cost, so changes in supply-side policies can be reflected by adjusting unit cost $\mathrm{Cu}$ and $\mathrm{Cb}$. Enterprise will only consider digital transformation when the transformation cost is less than the enterprise's present capital.

The main function of demand-side policies is the facilitation of transformation through an increase in market demand, so the paper uses $p 1$ to represent the enterprise's willingness to transform due to market demand and by adjusting $p 1$ to achieve the role of controlling demand policies.

The function of environmental policies is the facilitation of individuals' willingness to transform through isomorphic pressure; that is, if the digital level of a company's cooperative enterprise is higher, the stronger the willingness of the company to digitally transform in order to narrow the gap between itself and the cooperative enterprise. So, this paper obtains isomorphic pressure based on digital levels of cooperative enterprises of the enterprise. To be specific, if enterprise $a$ has $k$ cooperative enterprises, in which digital levels are $D_{1}, D_{2}, \ldots, D_{k}$, respectively, and then neighbors' isomorphic pressure on enterprise $a$ is represented as

$$
p 2=\frac{\max _{i}\left(D_{i}-D_{a}\right)}{D_{a}} .
$$

The impact of neighbors' isomorphic pressure on the enterprise is represented as $p 2 \times \mathrm{pr}$. Among which, pr refers the coefficient of neighbors' isomorphic pressure; i.e., coefficient of environmental policies' influences on the enterprise's willingness to transformation. By adjusting $p 2$, we can adjust the impact of environmental policies on the enterprise's willingness to transform. 
To sum up, enterprise's digital transformation

willingness can be represented as

$$
P= \begin{cases}0, & \text { if the expected digital transformation cost }<\text { present capital } \\ p 1+p 2 \times p r, & \text { otherwise. }\end{cases}
$$

Upon acquirement of each enterprise's digital transformation willingness $P$, the enterprise will choose to carry out digital transformation or not based on probability $P$. An additional IT application will be added to the network if all enterprises choose to carry out digital transformation succeed at it, in which eigenvector is a digital demand released by the environment. An edge will be added to the enterprise succeed at transformation and new IT application. The actual cost of an enterprise's digital transformation is a random number within $10 \%$ fluctuation of its expected cost.

(4) Stage of cooperative innovation. Upon the ending stage of digital transformation, enterprises start to think about whether they should carry out cooperative innovation, and each enterprise has three choices of no innovation, independent innovation, and cooperative innovation. Assume an enterprise knows selection made by all enterprises in the innovation ecosystem in the last round and their corresponding net income, then the enterprise may help its judgment on the selection of innovation mode based on other enterprises' experiences. If an enterprise chooses to cooperate innovation, the achievement of a cooperative relationship is determined by the enterprise's current innovation strategy, the digital level of the two enterprises, and whether the two enterprises have a cooperative relationship. Both independent innovation and cooperative innovation have an innovation success rate. The following article discusses it in detail:

Selection of innovation mode. Target on each enterprise divides enterprises of similar scale in the previous period into three types of no innovation, independent innovation, and cooperative innovation, calculates the average unit net income of those three types of enterprises, respectively, and divides the values by the sum of average unit net income of those three types of enterprises, which give you probabilities for the enterprise to choose those three innovation modes. Enterprise chooses the innovation strategy of the present period based on such probabilities. If the enterprise chooses no innovation, then no operation is required. If the enterprise chooses independent innovation, then the enterprise will succeed at innovation with a certain probability.
Selection of partner. If a certain enterprise intends to conduct cooperative innovation, then the enterprise will randomly send requests for cooperative innovation to an enterprise with a digital level no lower than it, and it is more likely for it to choose an enterprise worked with it before.

The invitee may accept or reject an invitation for cooperation, and factors affecting acceptance or rejection of cooperative innovation are as follows: (1) the enterprise's innovation strategy of the present period: if the invitee also chooses cooperative innovation, then the enterprise will consider invitation for such cooperative innovation; (2) digital levels of the two parties of cooperation: the more similar the digital levels of the two enterprises are, the more likely for them to encounter the same problem and thus have cooperative innovation; (3) existence of previous cooperative relations between the two parties: if the two parties had cooperation before, then regardless of invitee's current consideration of cooperative innovation and the digital levels of the two enterprises, the invitee will agree to carry out cooperative innovation.

If the invitee agrees to carry out cooperative innovation, then the two parties of cooperation start to carry out cooperation.

Success rate of innovation. Both independent innovation and cooperative innovation have success rate of innovation. Success rate of cooperative innovation $R_{c}$ is proportional to digital levels of the two parties of cooperation, to make sure success rate of cooperative innovation is a value between 0 and 1 , and this paper assumes $\quad R_{c}=\left(\left(\beta\left(\left(D_{A}+D_{B}\right) / 2\right)+\alpha_{1}\right) /\left(\beta\left(\left(D_{A}+\right.\right.\right.\right.$ $\left.\left.\left.D_{B}\right) / 2\right)+\alpha_{1}+1\right)$ ), in which $D_{A}$ and $D_{B}$ refer to digital levels of the two parties of cooperation, respectively. Success rate of independent innovation $R_{S}$ is proportional to the enterprise's own digital level and $R_{S}=\left(\beta D_{A}+\alpha_{2}\right) /\left(\beta D_{A}+\alpha_{2}+1\right)$, in which $\alpha_{1}$ and $\alpha_{2}$ control minimum value of success rate of transformation, while $\beta$ controls growth rate of success rate of transformation. Previous researches have shown that success rate of independent innovation is normally greater than success rate of cooperative innovation, so $\alpha_{1}<\alpha_{2}$. An edge with weight of 1 will be added to two enterprises if they succeed at cooperative innovation.

(5) Redistribution of market share. The market redistributes market share based on the market share of previous period and successful innovation activities 
of the present period. Enterprises that innovate successfully will gain more market share in the next round of competition. Therefore, this article designs the method of calculation of new market share as follows: assume $10 \%$ of whole market share is occupied by enterprises succeed at innovation, and the remaining $90 \%$ is occupied by all enterprises in the market based on the market share of the last round. Among enterprises succeed at innovation, the average increase in market share brought by cooperative innovation is higher than that brought by independent innovation, and enterprises choose cooperative innovation will distribute an increase in market share by business scale. To be specific, the base of an increase in market share of an enterprise chooses independent innovation is $1 \times r_{1}$, base of total increase in market share of two enterprises choose cooperative innovation is $2 \times r_{2}$, and the two parties of cooperation will further distribute the base of increase in market share of $2 \times r_{2}$ by business scale, in which $r_{1}$ is a random number between [0.9, 1.1] and $r_{2}$ is a random number between [1.0, 1.2].

For example, if there are 4 enterprises and the total market share is 100 , the market shares of each enterprise in the previous period are 10, 20, 30, and 40 . In the current period, enterprise 1 chose not to innovate, enterprises 2 and 4 chose cooperative innovation and succeeded, and enterprise 3 chose independent innovation and succeeded. The new market share allocation method is as follows:

$10 \%$ of the total market share (10) is divided among companies 2, 3, and 4. Enterprises 2 and 4 choose cooperate innovation and thus randomly select a value of $r_{2}$ from [1.0, 1.2]; assume the value is 1.1, then the sum of the market share gain base of these two enterprises is $2 \times 1.1=2.2$, and because the ratio of the scale of enterprises 2 and 4 is $1: 2$, the market share gain base of enterprise 2 is $2.2^{*}(1 / 3)=0.73$ and the market share gain base of enterprise 4 is $2.2^{*}$ (2/ $3)=1.47$. Enterprise 3 chooses independent innovation and succeeded; thus, we take a random number from $[0.9,1.1]$; assume it is 1 , then the market share gain base of enterprise 2 is 1 . Therefore, companies 2,3 , and 4 will share $10 \%$ of the market share at a ratio of $0.73: 1: 1.47$, and the remaining $90 \%$ of the market share will be shared by 4 companies at a ratio of $1: 2: 3: 4$. The final new market shares of the four companies are as follows: 9, 20.3, 30.1, and 40.6.

Enterprise's net income is proportional to its market share; if the net income of each unit market share is UNI, then the enterprise's net income $=$ the enterprise's market share $\times$ UNI.

3.5. Parameters and Their Initialization. Table 1 lists summarized parameters involved in the model and their values in this paper.
The four parameters of $\mathrm{Cu}, \mathrm{Cb}, \mathrm{pl}$, and pr control the effects of supply-side policies, demand-side policies, and environmental policies, respectively. In experiments of this paper, we will make other parameters unchanged and adjust aforesaid four parameters to study impacts of different policies on enterprises' digital transformation and evolution of innovation ecosystem.

\section{Numerical Experiments}

Supply-side policies, demand-side policies, and environmental policies can all affect enterprises' digital transformation and thus affect structure of innovation ecosystem. This paper conducts contrast experiments from perspectives of transformation willingness, transformation proportion, digital level, and net income of enterprises in innovation ecosystem as well as network structure of innovation ecosystem.

4.1. Impacts of Supply-Side Policies on Transformation. Impacts of supply-side policies on digital transformation are mainly reflected by transformation cost. Digital transformation cost is controlled by parameters of $\mathrm{Cu}$ and $\mathrm{Cb}$, among which $\mathrm{Cu}$ is the unit cost required for enterprise to upgrade existing IT application and $\mathrm{Cb}$ is the unit cost required for enterprise to create new IT application. To study impacts of supply-side policies on ecosystem, this section fixes parameters of $p 1=0.5, \mathrm{pr}=0.5$, and $R=60$ first, assumes (a) $\mathrm{Cu}=2, \mathrm{Cb}=4$, (b) $\mathrm{Cu}=1.5, \mathrm{Cb}=3$, (c) $\mathrm{Cu}=1$, $\mathrm{Cb}=2$, and (d) $\mathrm{Cu}=0.5, \mathrm{Cb}=1$ respectively, and conducts four groups of multiagent simulations. Related experiment results are as follows.

4.1.1. Enterprises' Transformation Willingness. Figure 1 shows distribution of enterprises' willingness to carry out digital transformation at different values of unit transformation cost, the $x$-axis shows enterprises' willingness to carry out digital transformation, and the $y$-axis shows number of enterprises willing to transform. If an enterprise's willingness to carry out digital transformation is 0 , it means the enterprise does not want to carry out digital transformation due to limited fund, insufficient expected income from digital transformation, and other reasons.

It can be seen from the figure that when digital transformation cost is relatively high, most enterprises will be unable to carry out digital transformation due to limited fund and other factors (when $\mathrm{Cu}=2$ and $\mathrm{Cb}=4$, around 950 enterprises have transformation willingness of 0 in the present period), and only few enterprises are willing to carry out digital transformation. Accompanied with reduction in digital transformation cost, an increasing number of enterprises show relatively strong willingness to carry out digital transformation (when $\mathrm{Cu}=0.5$ and $\mathrm{Cb}=1$, only around 75 enterprises have transformation willingness of 0 in the present period). 
TABle 1: Parameters involved in the model and their values.

\begin{tabular}{lcc}
\hline Symbol & Parameter description & Value \\
\hline$M$ & Enterprises number & 1000 \\
$N$ & Initial IT application number & 10 \\
$R$ & Total number of iterations & 60 \\
$\mathrm{MS}$ & Market size of whole network & 10000 \\
$p 1$ & Demand-side policies' influence on the enterprise's willingness to transformation & $0.3,0.5,0.7$ \\
$\mathrm{pr}$ & Coefficient of environmental policies' influence on the enterprise's willingness to transformation & $0.3,0.5,0.7$ \\
$T_{k}$ & Threshold of the minimum number of mismatches & 3 \\
$\mathrm{Cu}$ & Unit cost for upgrading of existing IT application & $0.5,1,1.5,2$ \\
$\mathrm{Cb}$ & Unit cost for building of new IT application & $1,2,3,4$ \\
$\mathrm{UNI}$ & Net income of each unit market share & 1 \\
$\alpha_{1}$ & Parameter of the success rate of cooperative innovation & 0.5 \\
$\alpha_{2}$ & Parameter of the success rate of independent innovation & 1 \\
$\beta$ & Parameter controlling the growth rate of success rate of transformation & 0.1 \\
\hline
\end{tabular}

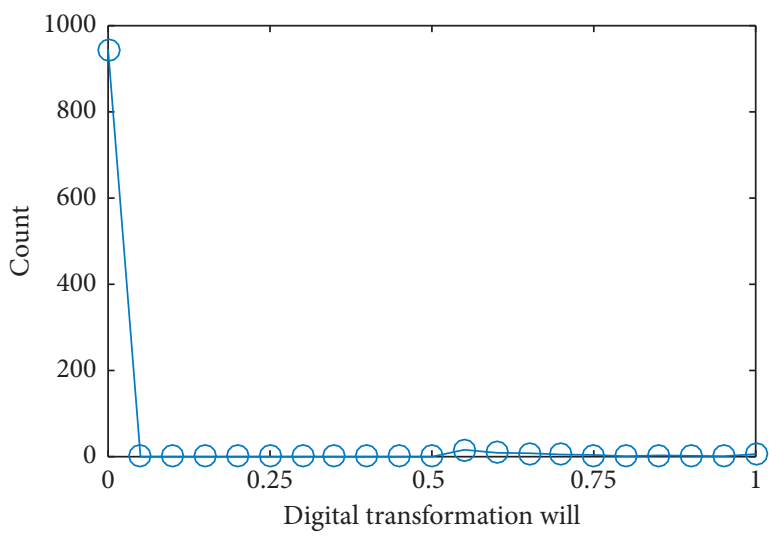

(a)

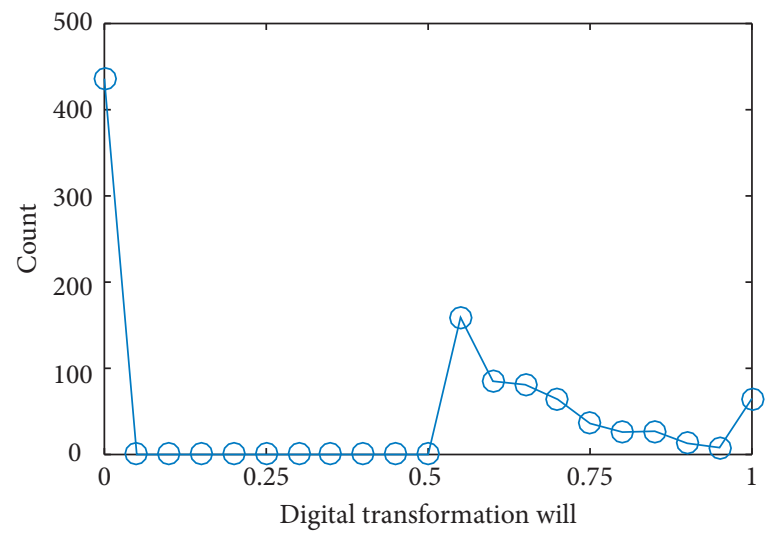

(c)

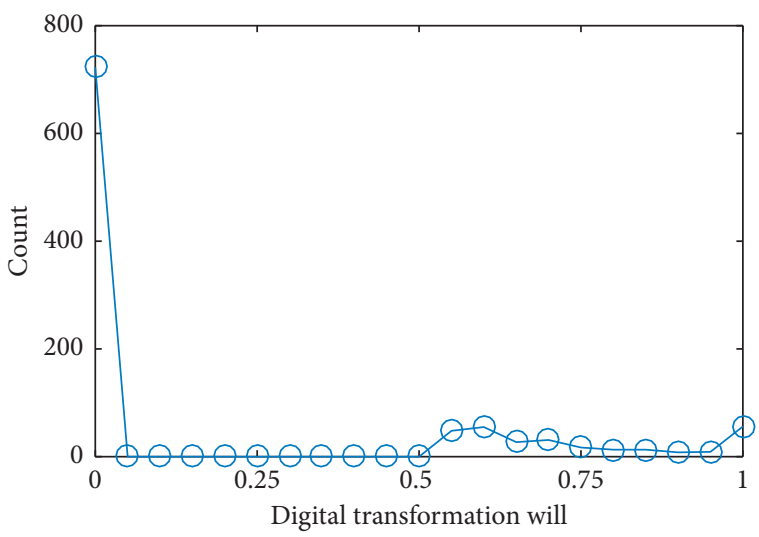

(b)

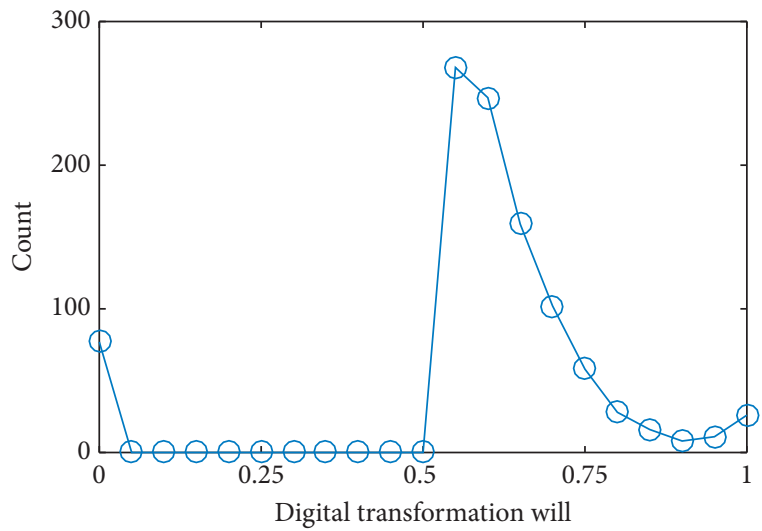

(d)

Figure 1: Enterprises' willingness to transformation at different values of unit transformation cost: (a) $\mathrm{Cu}=2, \mathrm{Cb}=4 ;(\mathrm{b}) \mathrm{Cu}=1.5, \mathrm{Cb}=3$; (c) $\mathrm{Cu}=1, \mathrm{Cb}=2 ;(\mathrm{d}) \mathrm{Cu}=0.5, \mathrm{Cb}=1$.

\subsubsection{Enterprises' Transformation Proportion. Figure 2} shows proportions of enterprises carry out digital transformation under different transformation costs, in which the $x$ axis shows number of periods of digital transformation and the $y$-axis shows proportion of enterprises carry out digital transformation in the $R$ period in innovation ecosystem.

It can be seen from the figure that the number of enterprises carrying out digital transformation in innovation ecosystem constantly increases with time. However, the higher the transformation cost, the slower the proportion grows. When digital transformation cost is comparatively high (Figure 2(a)), only around 65\% of enterprises eventually possess digital technology. Accompanied with continuous reduction in digital transformation cost, the number of enterprises succeed at digital transformation continuously increases, and all enterprises in innovation ecosystem will accomplish digital transformation if transformation cost is low enough (Figure 2(d)). 


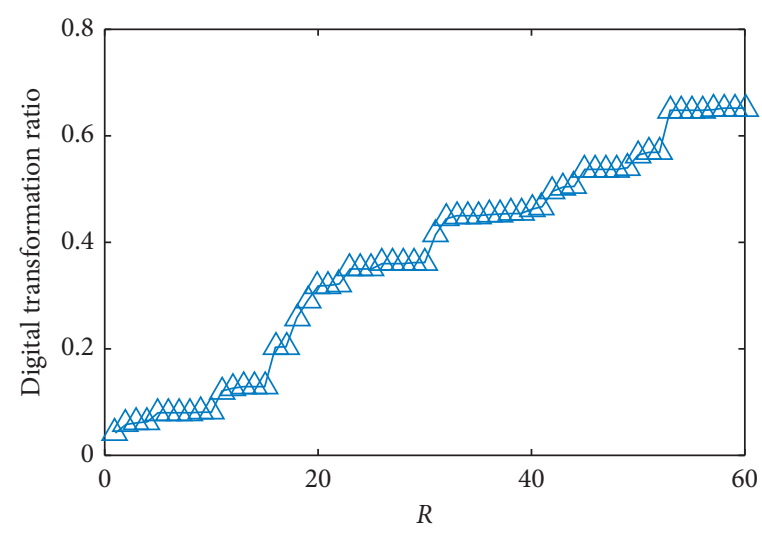

(a)

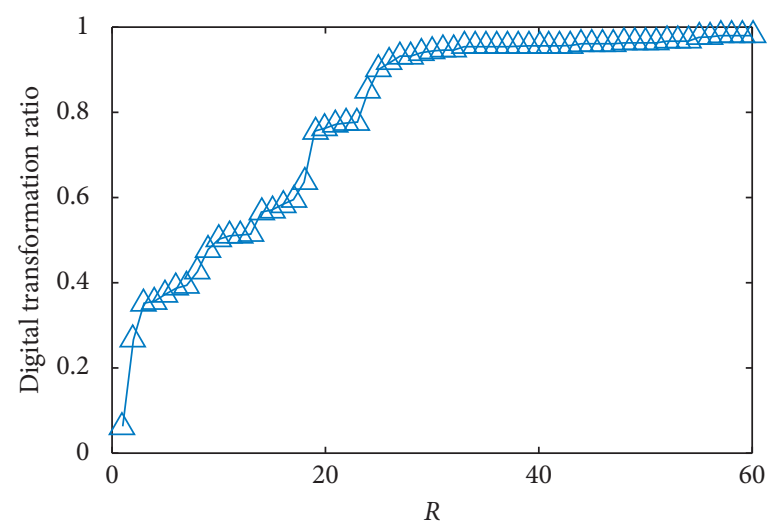

(c)

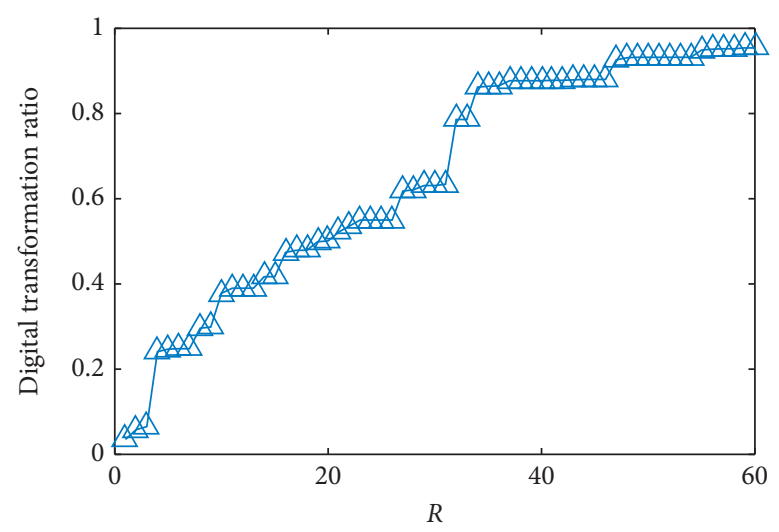

(b)

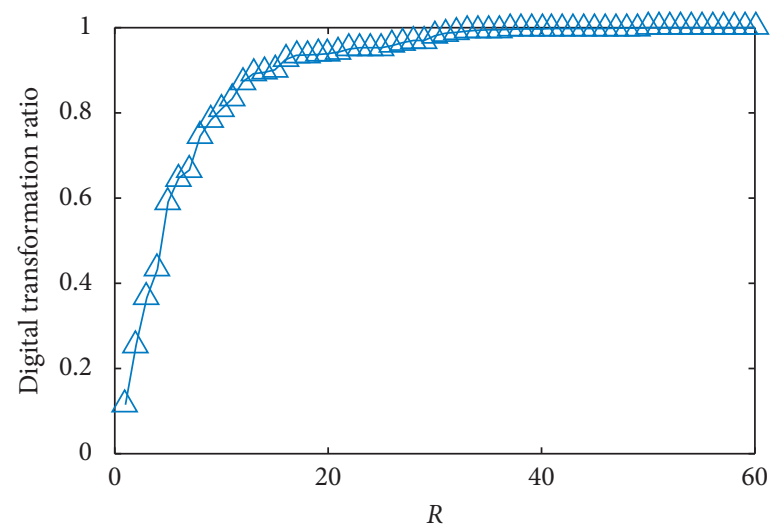

(d)

Figure 2: Proportions of enterprises carry out digital transformation under different transformation costs: $(\mathrm{a}) \mathrm{Cu}=2, \mathrm{Cb}=4 ;(\mathrm{b}) \mathrm{Cu}=1.5$, $\mathrm{Cb}=3$; (c) $\mathrm{Cu}=1, \mathrm{Cb}=2$; (d) $\mathrm{Cu}=0.5, \mathrm{Cb}=1$.

4.1.3. Enterprises' Digital Levels. Figure 3 shows the digital levels distribution of enterprises succeed at digital transformation under different transformation costs when $R=60$, $x$-axis shows digital levels, and $y$-axis shows number of enterprises with such digital level.

It can be seen from the figure that when the transformation cost is relatively high, distribution of enterprises' digital levels is similar to a long-tailed distribution, most enterprises have very low digital level, and few enterprises have relatively a high digital level. Accompanied with constant reduction of transformation cost, distribution of enterprises' digital levels gradually leans toward inverted U-shaped distribution, most enterprises have intermediate digital level, and few enterprises have very high or low digital level. Besides, accompanied with continuous reduction of transformation cost, the peak value of the inverted U-shaped distribution gradually moves to the right. In other words, reduction of digital transformation cost can give the whole innovation ecosystem a higher digital level.

4.1.4. Enterprises' Net Income. This section discusses relations between enterprises' net income and their digital levels under different transformation costs when $R=60$. The results are as indicated in Figure 4, in which $x$-axis shows digital levels of enterprises and $y$-axis shows net income of enterprises with such digital level. Each circle in the figure represents an enterprise; the more dense the circles in an area, the more the enterprises with such digital level and net income.

It can be seen from Figure 4 that, regardless of changes in digital transformation cost, enterprises with high digital levels tend to have a greater net income. However, when digital transformation cost is relatively high, enterprises will be more centralized at a lower left corner. In other words, most enterprises have low digital levels and net income, and there is a huge gap between enterprises with high net income and enterprises with low net income, which can easily result in monopoly. When enterprises' digital transformation cost is gradually reduced, most enterprises are gradually centralized in the middle, and the gap between net income of enterprises gradually decreases. It means when digital transformation cost is reduced, more enterprises will be able to carry out cooperative innovation through digital transformation and thus occupy market share. The ecosystem boasts of comparatively intense competition, and so-called "leading enterprise" has less obvious advantage.

4.1.5. Network Structure. Figure 5 shows the visual graph of cooperative innovation structure under four types of digital transformation costs when other parameters remain 


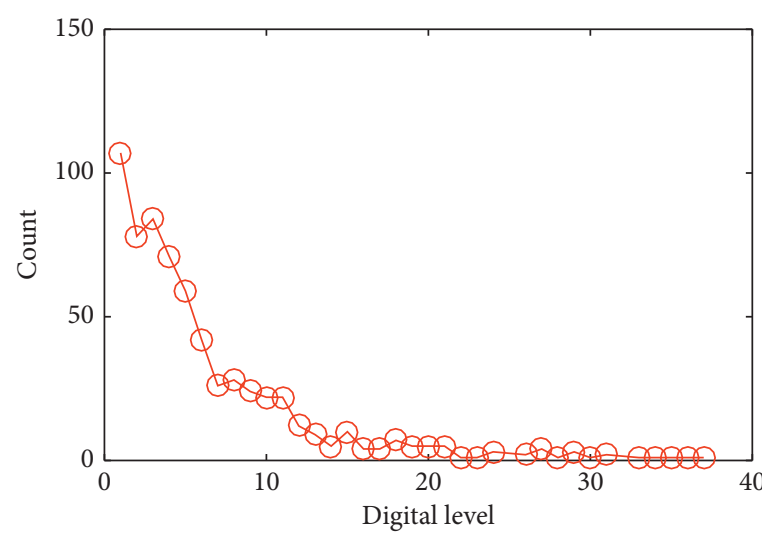

(a)

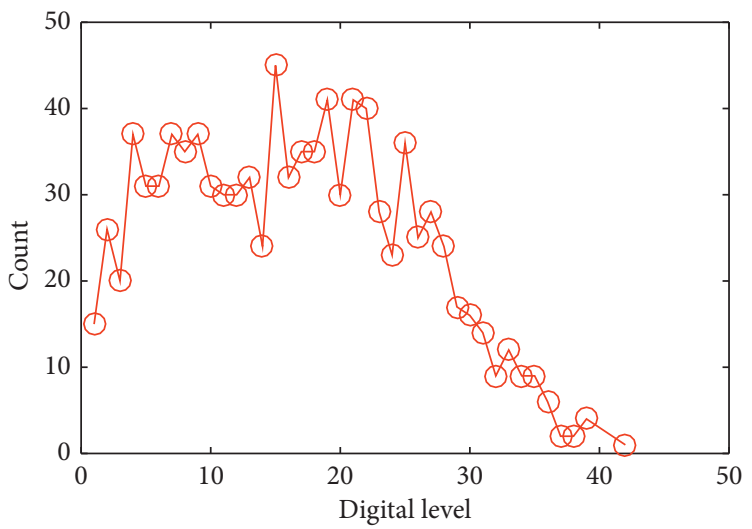

(c)

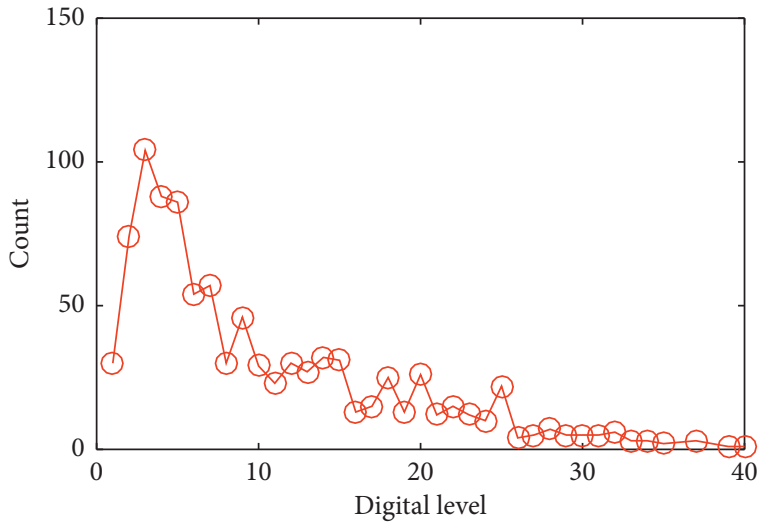

(b)

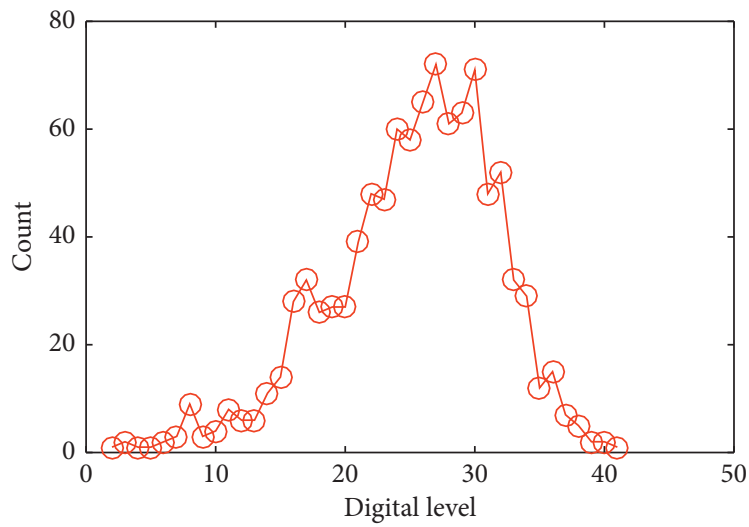

(d)

Figure 3: Digital level distribution of enterprises under different transformation costs: (a) $\mathrm{Cu}=2, \mathrm{Cb}=4 ;(\mathrm{b}) \mathrm{Cu}=1.5, \mathrm{Cb}=3$; (c) $\mathrm{Cu}=1$, $\mathrm{Cb}=2$; (d) $\mathrm{Cu}=0.5, \mathrm{Cb}=1$.

unchanged and $R=60$. Table 2 shows partial indicators of cooperative innovation network, in which islands number $\left(N_{I}\right)$ indicates the number of enterprises not participating in cooperative innovation. Average number of cooperative enterprises $\left(A_{C E}\right)$ indicates the average number of enterprises has cooperative innovation with each enterprise during evolution of whole innovation ecosystem. The average number of cooperation $\left(A_{C}\right)$ indicates many successful cooperative innovations each company has carried out on average. If the average number of cooperation is greater than average number of cooperative enterprises, it means some enterprises have multiple collaborations.

It can be seen from aforesaid figure that cooperative innovation network in innovation ecosystem has an obvious core-periphery structure. In other words, only few enterprises in the network can have cooperative relations with numerous enterprises, and those enterprises connect with each other and form the "core" of the network. Most enterprises only have cooperative relations with one or two enterprises, and the sparse connections between those enterprises form the "periphery" of the network. This paper uses $K$-core [27] to gradually remove nodes and edges on the edge of network and acquires a subnetwork located at the core of network. Table 2 shows corresponding average number of cooperative enterprises $\left(A_{C E} S\right)$ and average number of cooperation $\left(A_{C} S\right)$ of each enterprise in those subnetworks. When digital level gradually decreases, average number of cooperative enterprises of core enterprises gradually increases at low speed, average number of cooperation between core enterprises rises significantly, and core parts of the network are connected more closely. The potential cause of this phenomena is accompanied with reduction in digital transformation cost, more enterprises have the chance to carry out digital transformation, digital levels of different enterprises in the network become more decentralized, and available cooperative partners of each enterprise intend to carry out cooperative innovation become more centralized, which makes it easier to form longterm stable cooperative relations. It is reflected by constantly strengthening cooperation between core enterprises from the perspective of network structure.

4.2. Impacts of Demand-Side Policies on Innovation Ecosystem. In the model of this paper, demand-side policies are controlled by parameter $p 1$; the greater the $p 1$, the more powerful the demand-side policies. To study impacts of demand-side policies on innovation ecosystem, this section fixes parameters of $\mathrm{pr}=0.5$ and $R=60$ based on experiment results of previous section, assumes (a) $p 1=0.3, \mathrm{Cu}=1, \mathrm{Cb}=2$; (b) 


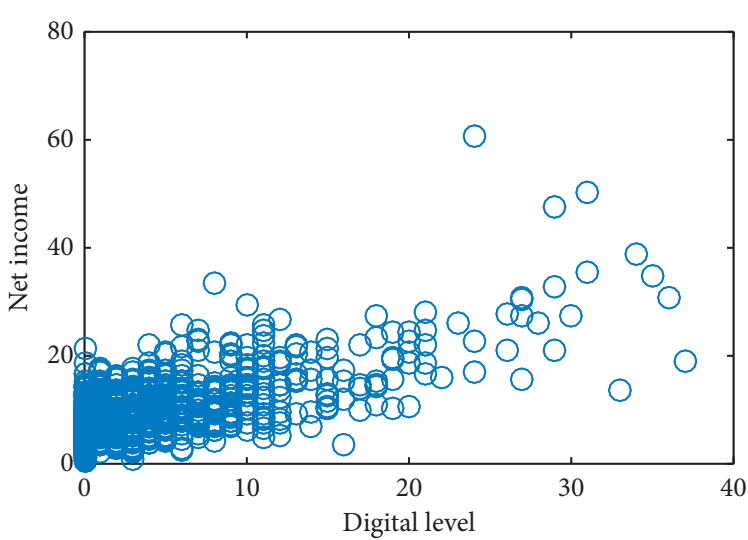

(a)

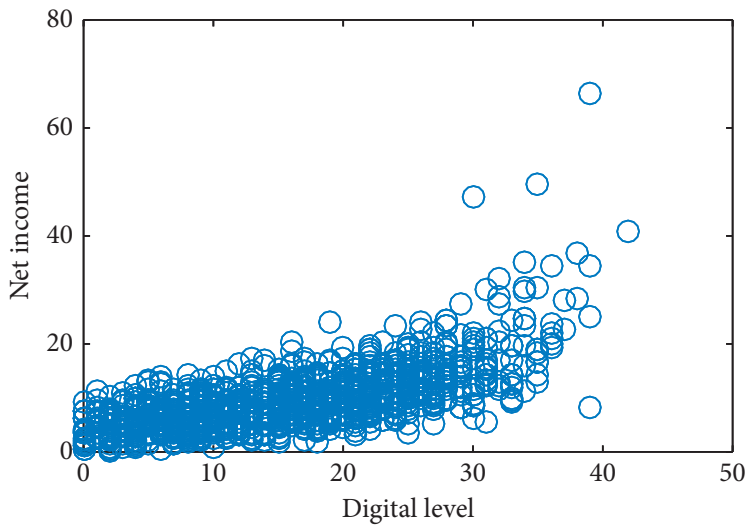

(c)

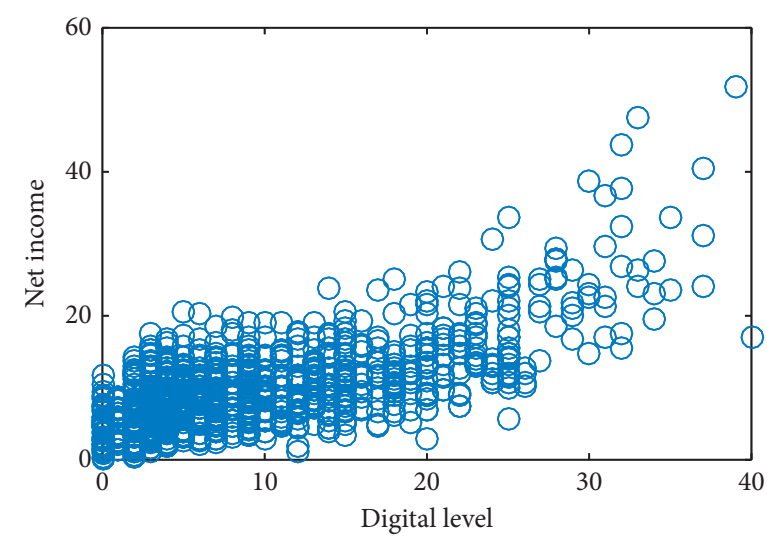

(b)

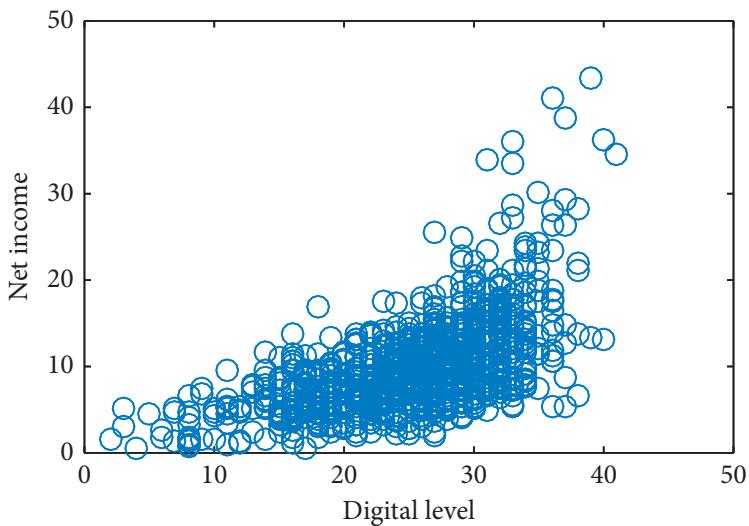

(d)

FIGURE 4: Enterprises' net income under different transformation costs: (a) $\mathrm{Cu}=2, \mathrm{Cb}=4 ;(\mathrm{b}) \mathrm{Cu}=1.5, \mathrm{Cb}=3 ;(\mathrm{c}) \mathrm{Cu}=1, \mathrm{Cb}=2 ;(\mathrm{d})$ $\mathrm{Cu}=0.5, \mathrm{Cb}=1$.

$p 1=0.5, \mathrm{Cu}=1, \mathrm{Cb}=2 ;(\mathrm{c}) p 1=0.7, \mathrm{Cu}=1, \mathrm{Cb}=2 ;(\mathrm{d}) p 1=0.3$, $\mathrm{Cu}=2, \mathrm{Cb}=4$; (e) $p 1=0.5, \mathrm{Cu}=2, \mathrm{Cb}=4$; and (f) $p 1=0.7$, $\mathrm{Cu}=2, \mathrm{Cb}=4$, respectively, and conducts six groups of multiagent simulations for validation of effects of demand-side policies under two conditions of relatively low transformation cost and relatively high transformation cost. Related experiment results are as follows.

4.2.1. Enterprises' Transformation Willingness. Figure 6 shows distribution of enterprises' transformation willingness under different demand-side policies when $R=60$. The first row shows the situation when digital transformation cost is relatively low, and the second row shows the situation when digital transformation cost is relatively high. It can be seen from the figure that, at the same digital transformation cost, there is a small difference in number of enterprises willing to carry out digital transformation under different demand-side policies, but only feel enterprises have strong transformation willingness when $p 1$ is relatively small. Accompanied with a gradual increase in $p 1$, those willing to carry out digital transformation will all have strong transformation willingness.

Increase in digital transformation cost will lead to dramatic decrease in number of enterprises willing to carry out digital transformation, but changes in transformation cost will not change distribution of strengths of transformation willingness.

4.2.2. Enterprises' Transformation Proportion. Figure 7 show proportions of enterprises carry out digital transformation under demand policies of different strengths when $R=60$. The first row shows the situation when digital transformation cost is relatively low, and the second row shows the situation when digital transformation cost is relatively high. Regardless of changes in transformation cost, accompanied with strengthening of demand-side policies, enterprises choosing to carry out digital transformation continuously increase. However, when transformation cost is relatively low (the first row), since most enterprises can try digital transformation, the guiding role of demand-side policies is mainly reflected by acceleration of different enterprises' digital transformation, which allows enterprises in the whole ecosystem to realize digitalization ASAP. When transformation cost is relatively high, strengthening of demand-side policies can significantly increase proportion of enterprises carrying out digital transformation in the ecosystem (from under $60 \%$ in Figure $7(\mathrm{~d})$ to around $90 \%$ in Figure $7(\mathrm{f}))$. 


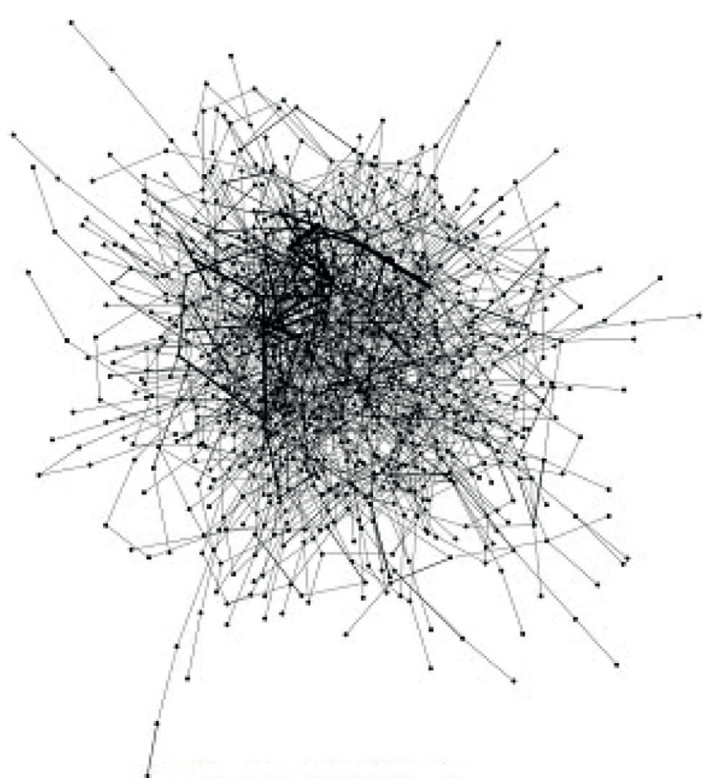

(a)

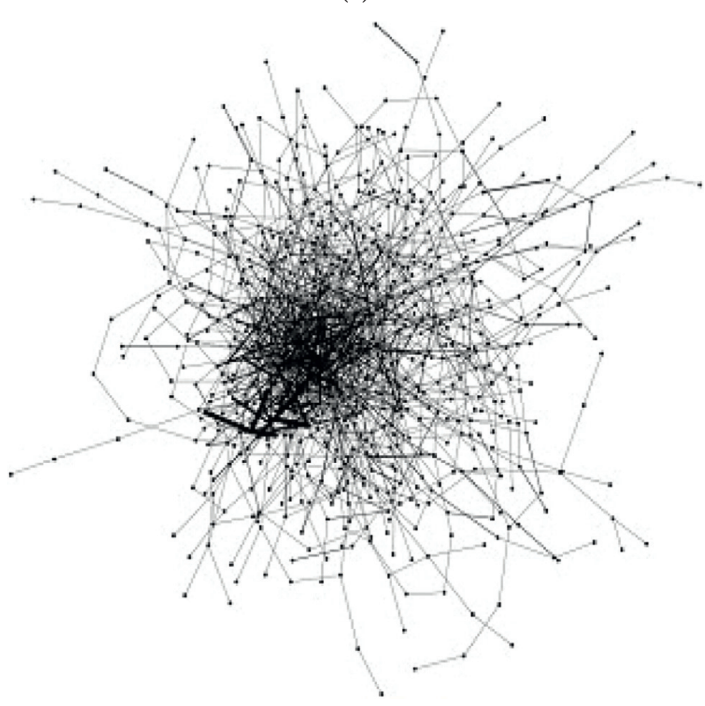

(c)

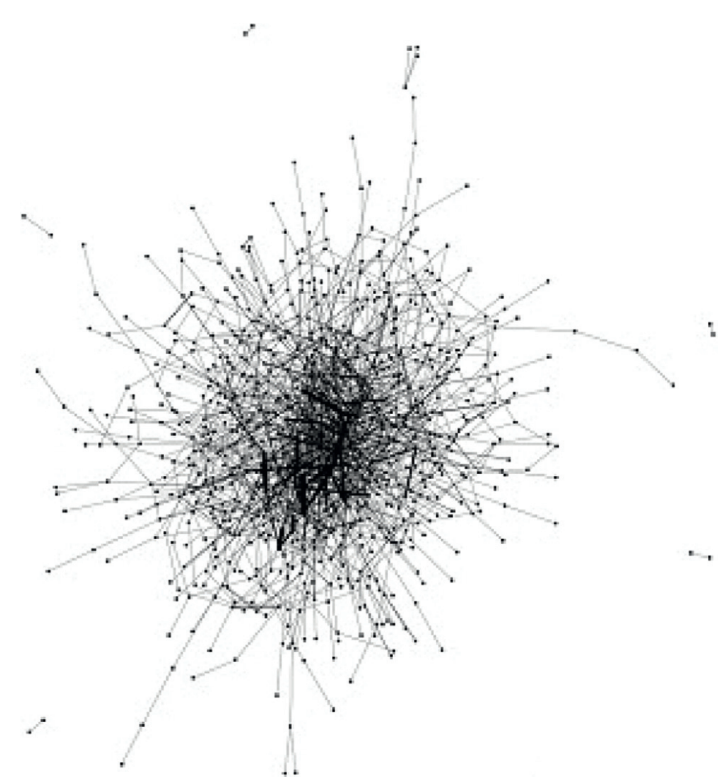

(b)

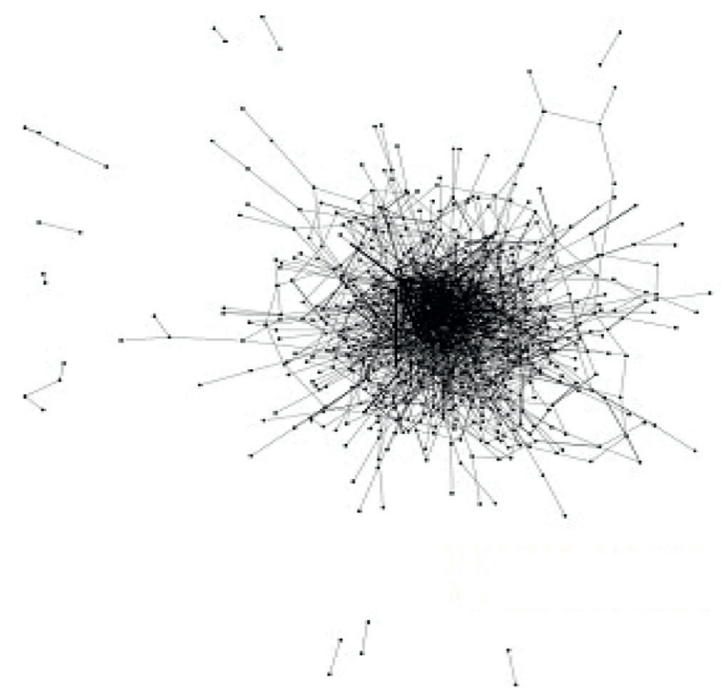

(d)

Figure 5: Network structures under different transformation costs: (a) $\mathrm{Cu}=2, \mathrm{Cb}=4 ;(\mathrm{b}) \mathrm{Cu}=1.5, \mathrm{Cb}=3 ;(\mathrm{c}) \mathrm{Cu}=1, \mathrm{Cb}=2 ;(\mathrm{d}) \mathrm{Cu}=0.5$, $\mathrm{Cb}=1$.

TABLE 2: The partial indicators of cooperative innovation network under different transformation costs.

\begin{tabular}{lcccrc}
\hline Costs & $N_{I}$ & $A_{C E}$ & $A_{C E \_} S$ & $A_{C}$ & $A_{C \_} S$ \\
\hline $\mathrm{Cu}=2, \mathrm{Cb}=4$ & 48 & 3.567 & 4.034 & 4.569 & 5.826 \\
$\mathrm{Cu}=1.5, \mathrm{Cb}=3$ & 67 & 3.479 & 4.49 & 4.797 & 7.565 \\
$\mathrm{Cu}=1, \mathrm{Cb}=2$ & 103 & 3.518 & 4.716 & 5.064 & 8.189 \\
$\mathrm{Cu}=0.5, \mathrm{Cb}=1$ & 95 & 4.393 & 5.702 & 5.943 & 10.298 \\
\hline
\end{tabular}

4.2.3. Enterprises' Digital Levels. Figure 8 shows distribution of digital levels of enterprises succeed at digital transformation under demand-side policies of different strengths when $R=60$. The first row shows the situation when digital transformation cost is relatively low, and the second row shows the situation when digital transformation cost is relatively high.
It can be seen from the figure that, regardless of changes in transformation cost, strengthening of demand-side policies will lead to gradual rise in average digital level and maximum digital level of enterprises in ecosystem. When $p 1=0.3,0.5$, and 0.7 , maximum digital levels of enterprises are around 30,40, and 50, respectively. However, increase in 


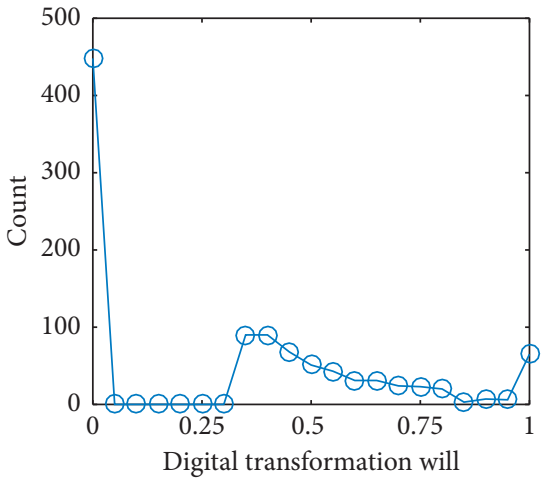

(a)

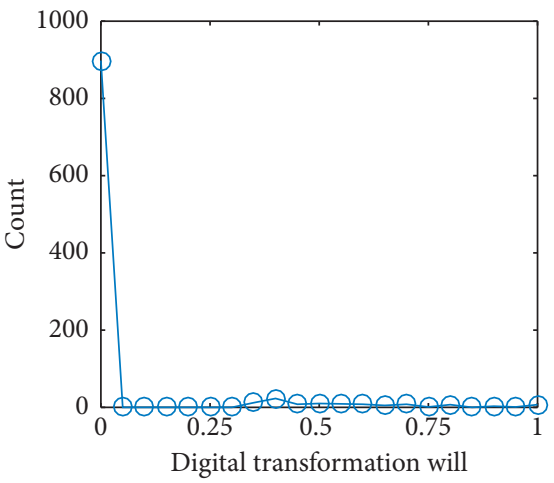

(d)

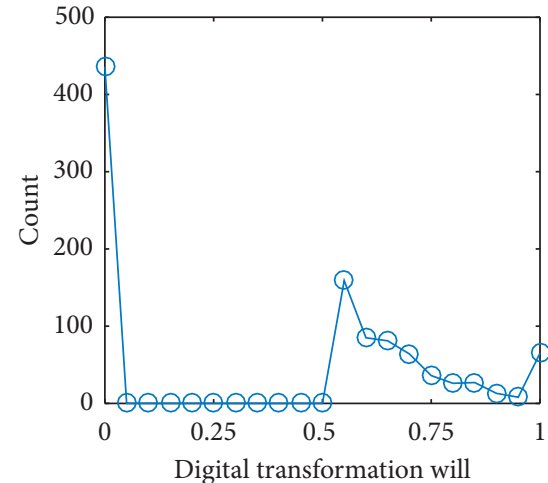

(b)

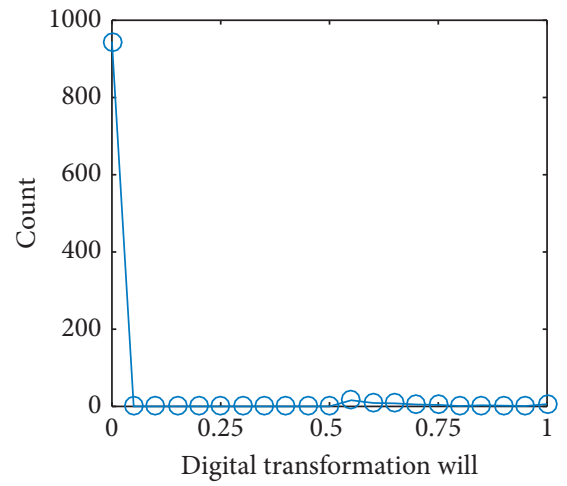

(e)

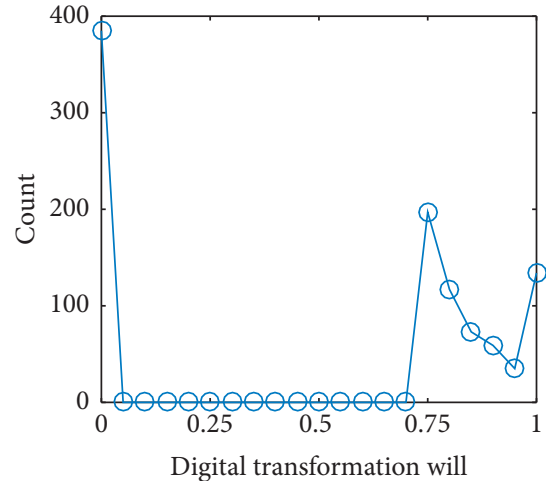

(c)

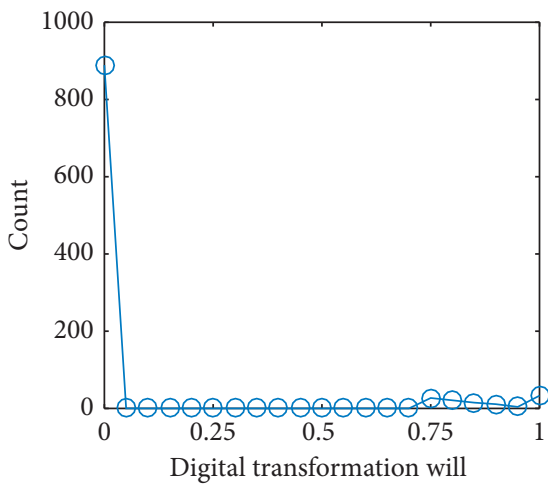

(f)

Figure 6: Enterprises' transformation willingness under different demand-side policies: (a) $\mathrm{p} 1=0.3, \mathrm{Cu}=1, \mathrm{Cb}=2 ;(\mathrm{b}) p 1=0.5, \mathrm{Cu}=1$, $\mathrm{Cb}=2$; (c) $p 1=0.7, \mathrm{Cu}=1, \mathrm{Cb}=2$; (d) $p 1=0.3, \mathrm{Cu}=2, \mathrm{Cb}=4$; (e) $p 1=0.5, \mathrm{Cu}=2, \mathrm{Cb}=4$; (f) $p 1=0.7, \mathrm{Cu}=2, \mathrm{Cb}=4$.

transformation cost will make most enterprises stay at relatively low digital levels and thus make average digital level of enterprise lower than that at low transformation cost, but maximum digital levels of enterprises remain unaffected.

4.2.4. Enterprises' Net Income. Figure 9 shows relations between digital level and net income of enterprises under demand-side policies of different strengths when $R=60$, in which the first row shows the situation when digital transformation cost is relatively low and the second row shows the situation when digital transformation cost is relatively high.

It can be seen from Figure 9 that enterprises with high digital levels all tend to possess greater net income, and it is a ubiquitous characteristic. Besides, changes in strengths of demand-side policies mainly change distribution of digital levels on $x$-axis, while net income of enterprises on $y$-axis do not change obviously with changes in strengths of demandside policies. The potential cause is strengthening of demand-side policies can gradually increase overall digital level of innovation ecosystem, but the market size is limited. So, when all enterprises possess certain digital level, the dividend from digital level will gradually decrease.

4.2.5. Network Structure. Table 3 shows partial indicators of cooperative innovation network under demand-side policies of different strengths when $R=60$. The lower the digital transformation cost, the stronger the demand-side policies, the greater the digital transformation willingness of enterprises, the higher the eventual digital level of innovation ecosystem, and the more obvious the core-periphery structure in the network. When digital transformation cost is relatively high, only few enterprises can carry out digital transformation, and most enterprises' digital levels are at a relatively low level. Although the network does have core-periphery structure, enterprises' willingness to carry out digital transformation has small impact on network structure.

4.3. Impacts of Environmental Policies on Innovation Ecosystem. This section studies impacts of environmental policies on enterprises' digital transformation, enterprises' net income distribution, and network structure of innovation ecosystem. Environmental policies are controlled by parameter $\mathrm{pr}$ in the model of this paper; the greater the pr, the greater the impact of other enterprises' isomorphic pressure on an enterprise's digital transformation. Similar to Section 4.2, this section fixes parameters of $p 1=0.5$ and $R=60$, assumes (a) $\mathrm{pr}=0.3, \mathrm{Cu}=1, \mathrm{Cb}=2$, (b) $\mathrm{pr}=0.5$, $\mathrm{Cu}=1, \mathrm{Cb}=2$, (c) $\mathrm{pr}=0.7, \mathrm{Cu}=1, \mathrm{Cb}=2$, (d) $\mathrm{pr}=0.3$, $\mathrm{Cu}=2, \mathrm{Cb}=4$, (e) $\mathrm{pr}=0.5, \mathrm{Cu}=2, \mathrm{Cb}=4$, and (f) $\mathrm{pr}=0.7$, $\mathrm{Cu}=2, \mathrm{Cb}=4$, respectively, and conducts six groups of multiagent simulations for validation of effects of 


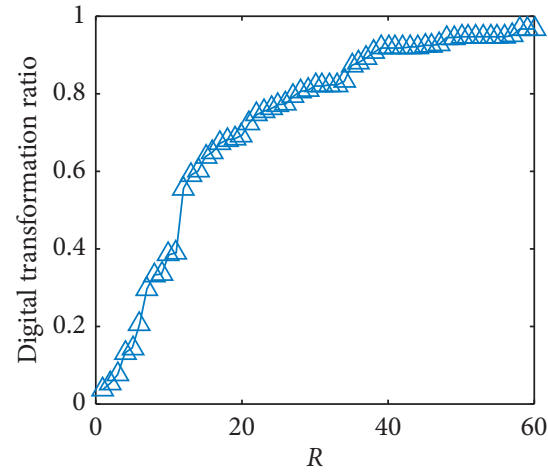

(a)

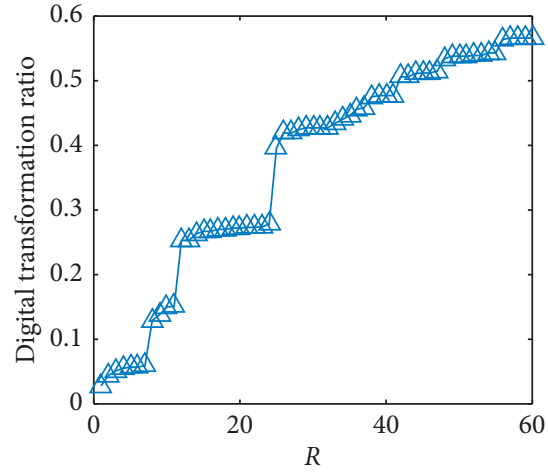

(d)

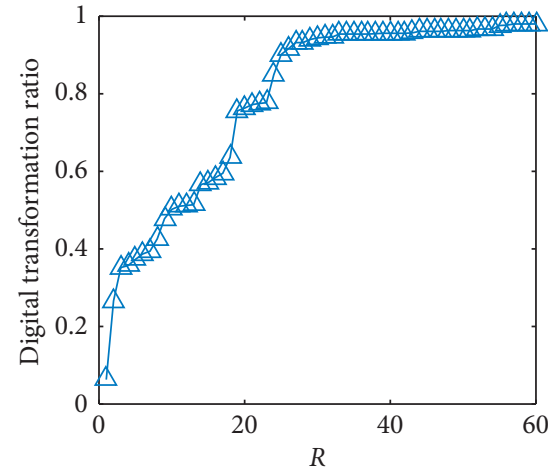

(b)

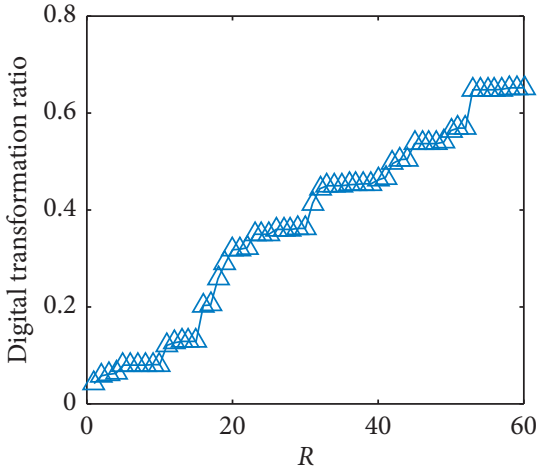

(e)

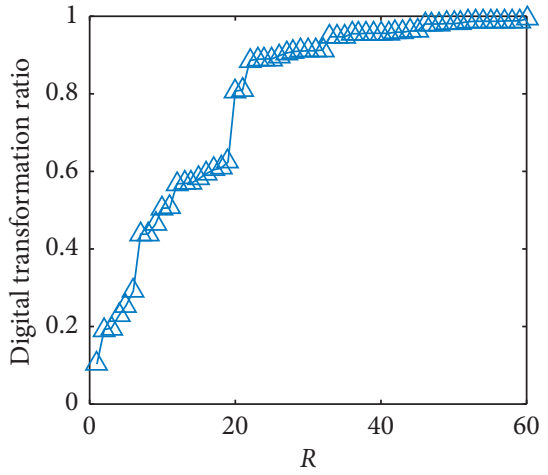

(c)

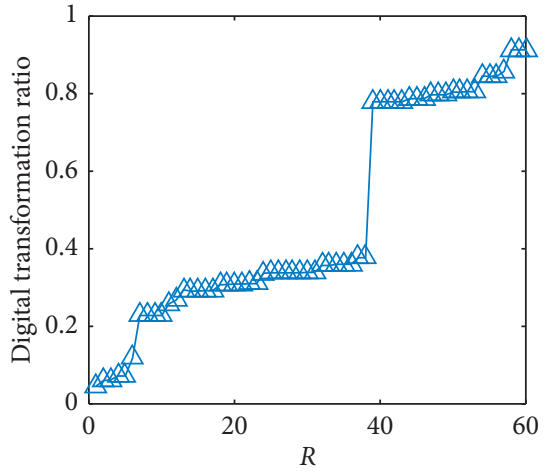

(f)

FiguRe 7: The proportions of enterprises carry out digital transformation under different demand-side policies: $(\mathrm{a}) p 1=0.3, \mathrm{Cu}=1, \mathrm{Cb}=2$; (b) $p 1=0.5, \mathrm{Cu}=1, \mathrm{Cb}=2 ;$ (c) $p 1=0.7, \mathrm{Cu}=1, \mathrm{Cb}=2$; (d) $p 1=0.3, \mathrm{Cu}=2, \mathrm{Cb}=4$; (e) $p 1=0.5, \mathrm{Cu}=2, \mathrm{Cb}=4 ;(\mathrm{f}) p 1=0.7, \mathrm{Cu}=2, \mathrm{Cb}=4$.

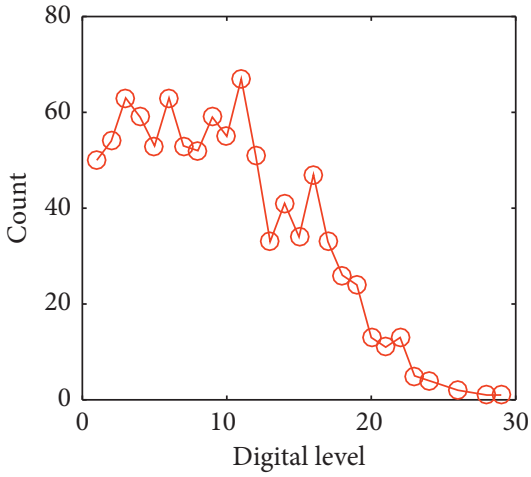

(a)

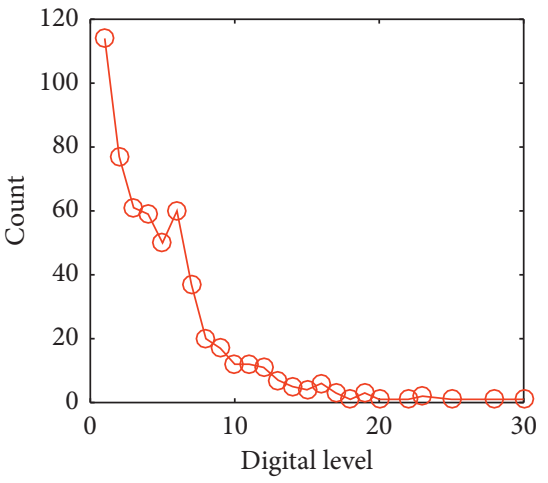

(d)

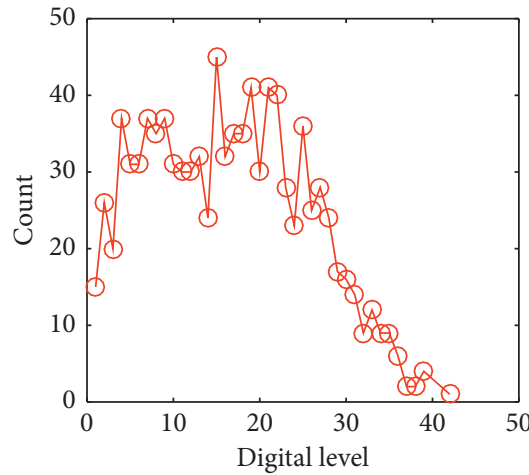

(b)

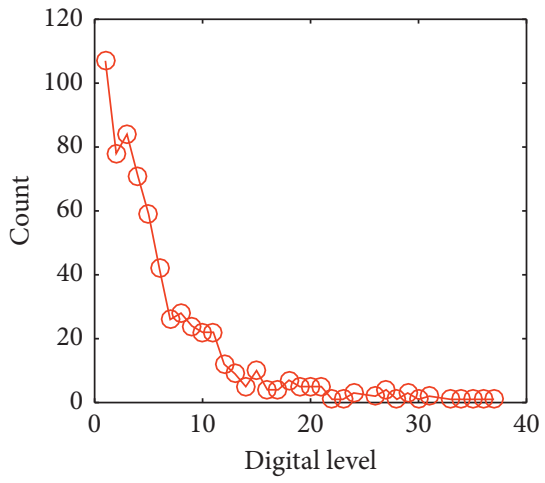

(e)

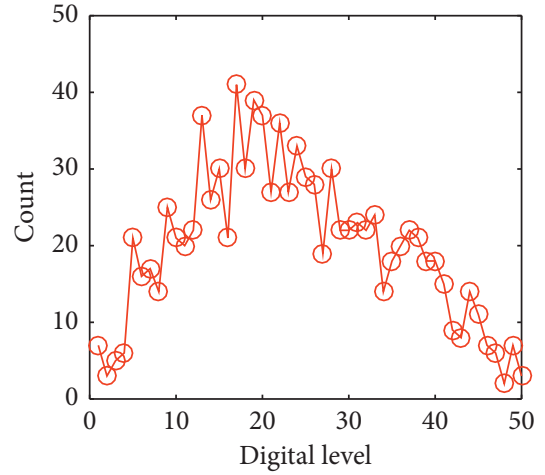

(c)

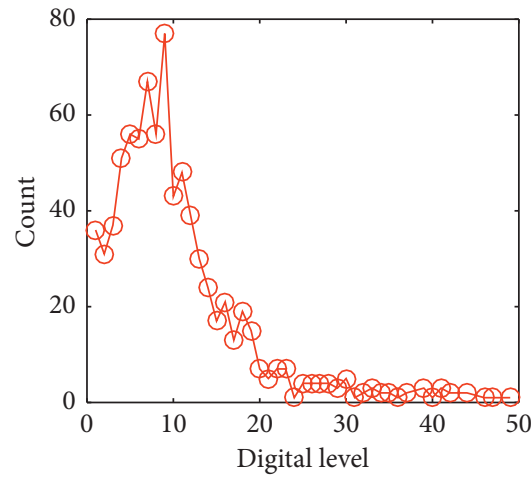

(f)

Figure 8: The digital levels of enterprises under different demand-side policies: (a) $p 1=0.3, \mathrm{Cu}=1, \mathrm{Cb}=2 ;(\mathrm{b}) p 1=0.5, \mathrm{Cu}=1, \mathrm{Cb}=2 ;(\mathrm{c})$ $p 1=0.7, \mathrm{Cu}=1, \mathrm{Cb}=2$; (d) $p 1=0.3, \mathrm{Cu}=2, \mathrm{Cb}=4$; (e) $p 1=0.5, \mathrm{Cu}=2, \mathrm{Cb}=4$; (f) $p 1=0.7, \mathrm{Cu}=2, \mathrm{Cb}=4$. 


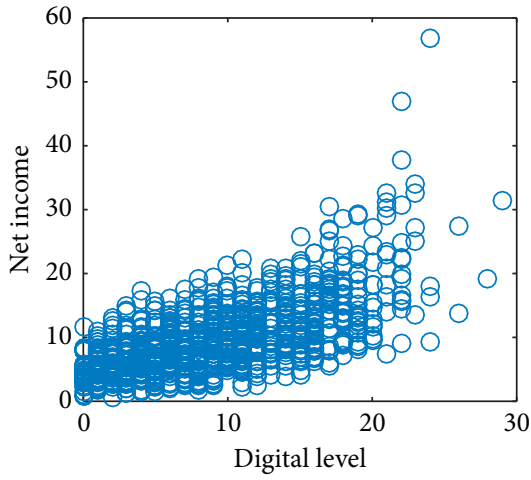

(a)

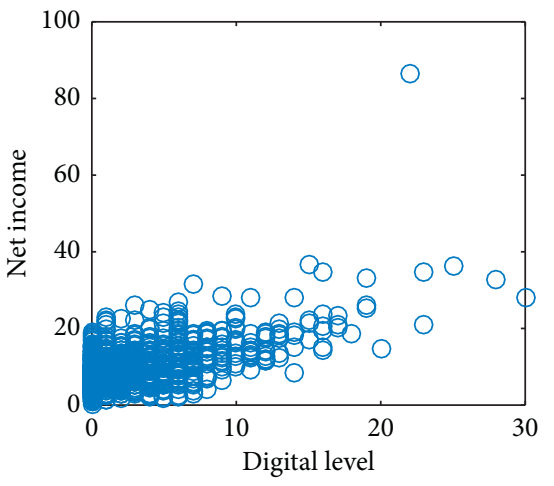

(d)

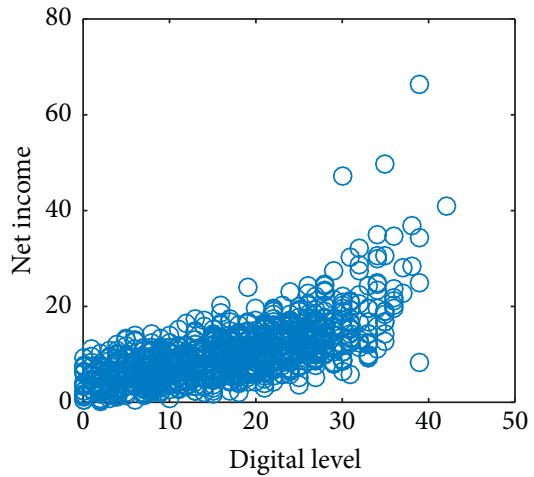

(b)

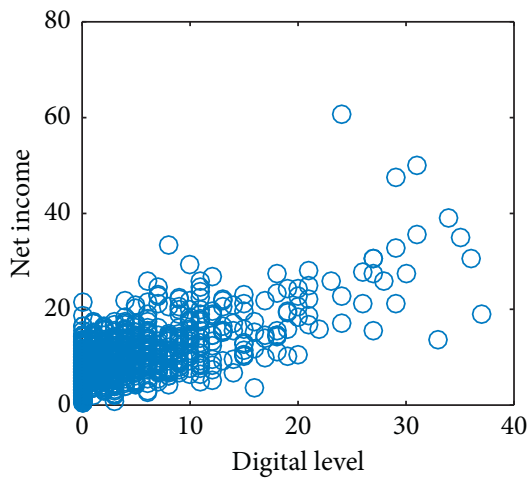

(e)

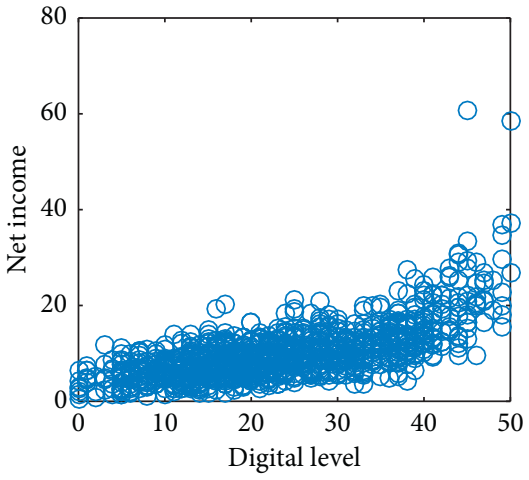

(c)

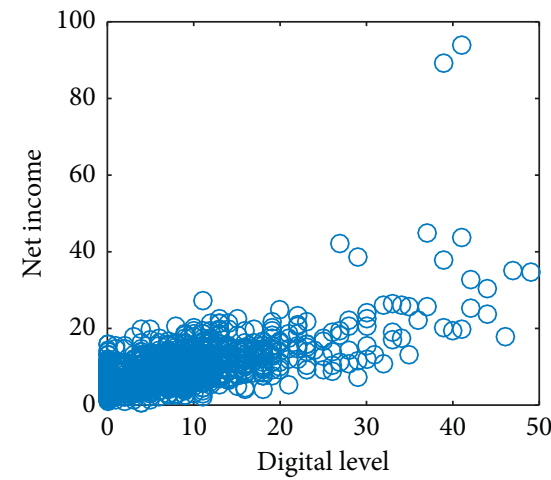

(f)

Figure 9: Enterprises' net income under different demand-side policies: (a) $p 1=0.3, \mathrm{Cu}=1, \mathrm{Cb}=2$; (b) $p 1=0.5, \mathrm{Cu}=1, \mathrm{Cb}=2$; (c) $p 1=0.7$, $\mathrm{Cu}=1, \mathrm{Cb}=2$; (d) $p 1=0.3, \mathrm{Cu}=2, \mathrm{Cb}=4$; (e) $p 1=0.5, \mathrm{Cu}=2, \mathrm{Cb}=4$; (f) $p 1=0.7, \mathrm{Cu}=2, \mathrm{Cb}=4$.

TABLE 3: The partial indicators of cooperative innovation network under different demand-side policies.

\begin{tabular}{lcccc}
\hline Costs & $N_{I}$ & $A_{C E}$ & $A_{C E \_} S$ & $A_{C}$ \\
\hline$p 1=0.3, p r=0.5, \mathrm{Cu}=1, \mathrm{Cb}=2$ & 94 & 4.011 & 4.908 & 5.341 \\
$p 1=0.5, \mathrm{pr}=0.5, \mathrm{Cu}=1, \mathrm{Cb}=2$ & 103 & 3.518 & 4.716 & 5.064 \\
$p 1=0.7, \mathrm{pr}=0.5, \mathrm{Cu}=1, \mathrm{Cb}=2$ & 111 & 3.386 & 4.743 & 5.093 \\
$p 1=0.3, \mathrm{pr}=0.5, \mathrm{Cu}=2, \mathrm{Cb}=4$ & 36 & 4.002 & 4.578 & 4.916 \\
$p 1=0.5, \mathrm{pr}=0.5, \mathrm{Cu}=2, \mathrm{Cb}=4$ & 48 & 3.567 & 4.034 & 4.189 \\
$p 1=0.7, \mathrm{pr}=0.5, \mathrm{Cu}=2, \mathrm{Cb}=4$ & 59 & 3.581 & 4.213 & 6.016 \\
\hline
\end{tabular}

environmental policies under two conditions of relatively low transformation cost and relatively high transformation cost. Related experiment results are as follows.

4.3.1. Enterprises' Transformation Willingness. Figure 10 shows distribution of enterprises' transformation willingness under different environmental policies when $R=60$. The first row shows the situation when digital transformation cost is relatively low, and the second row shows the situation when digital transformation cost is relatively high.

It can be seen from the figure that, at the same digital transformation cost, there is a small difference in number of enterprises willing to carry out digital transformation under different environmental policies, but the number of enterprises with high transformation willingness continuously increases accompanied with a gradual increase in $p 1$. This impact is similar to that of demand-side policies, but what different from demand-side policies is: under low level of demand-side policies, the minimum transformation willingness of enterprises willing to transform is also at a low level. Under high level of demand-side policies, the minimum transformation willingness of enterprises willing to transform is also at a high level, as indicated in Figure 6. However, regardless of level of environmental policies, the minimum transformation willingness of enterprises willing to transform is similar around 0.55, as indicated in Figure 10, and strengthening of environmental policies only makes enterprises' transformation willingness distributed more evenly. From the perspective of innovation 


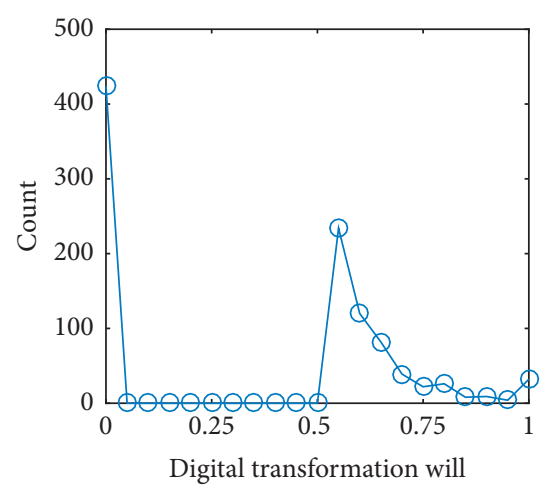

(a)

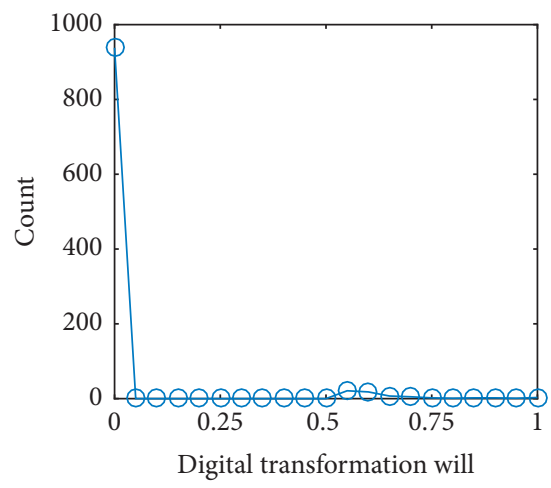

(d)

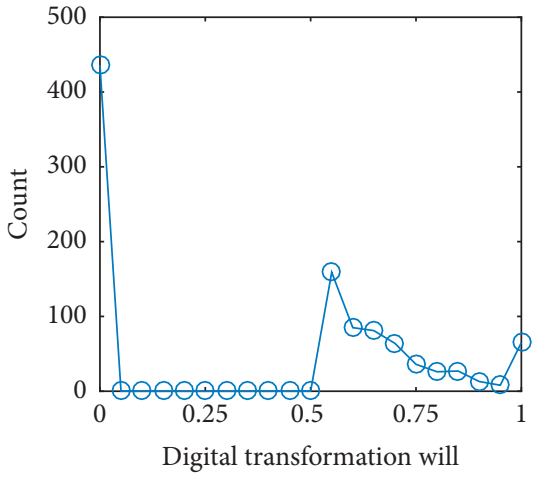

(b)

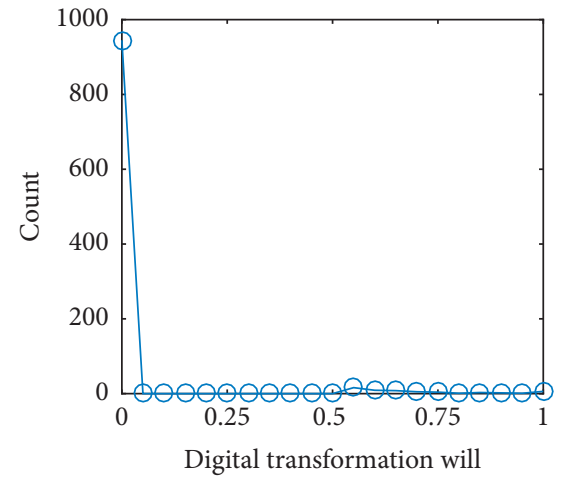

(e)

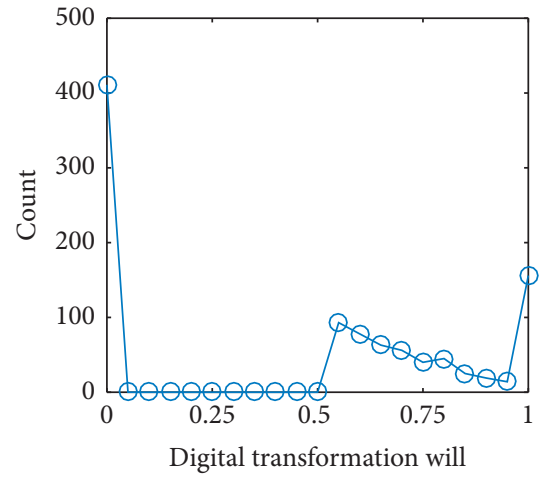

(c)

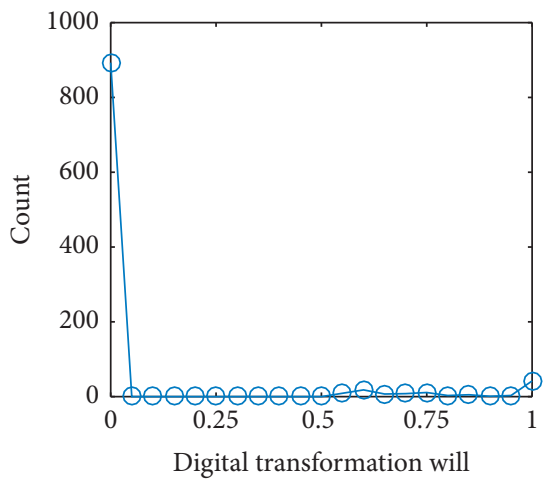

(f)

Figure 10: Enterprises' transformation willingness under different environmental policies: $(\mathrm{a}) \mathrm{pr}=0.3, \mathrm{Cu}=1, \mathrm{Cb}=2 ;(\mathrm{b}) \mathrm{pr}=0.5, \mathrm{Cu}=1$, $\mathrm{Cb}=2$; (c) $\mathrm{pr}=0.7, \mathrm{Cu}=1, \mathrm{Cb}=2$; (d) $\mathrm{pr}=0.3, \mathrm{Cu}=2, \mathrm{Cb}=4$; (e) $\mathrm{pr}=0.5, \mathrm{Cu}=2, \mathrm{Cb}=4$; (f) $\mathrm{pr}=0.7, \mathrm{Cu}=2, \mathrm{Cb}=4$.

ecosystem, it can be taken as demand-side policies' impacts on transformation willingness are more immediate and effective than environmental policies' impacts on transformation willingness.

4.3.2. Enterprises' Transformation Proportion. Figure 11 shows proportions of enterprises carry out digital transformation under different environmental policies. The first row shows the situation when digital transformation cost is relatively low, and the second row shows the situation when digital transformation cost is relatively high.

Regardless of changes in transformation cost, impacts of environmental policies on proportion of enterprises carrying out digital transformation are not as significant as impacts of demand-side policies.

4.3.3. Enterprises' Digital Levels. Figure 12 shows distribution of digital levels of enterprises succeed at digital transformation under different environmental policies when $R=60$. The first row shows the situation when digital transformation cost is relatively low, and the second row shows the situation when digital transformation cost is relatively high.
It can be seen from the figure that, regardless of changes in transformation cost, strengthening of environmental policies will make average digital level of enterprises in ecosystem gradually increase, but the effects of environmental policies are less significant in comparison with demand-side policies.

4.3.4. Enterprises' Net Income. Figure 13 shows relations between digital level and net income of enterprises under different environmental policies when $R=60$, in which the first row shows the situation when digital transformation cost is relatively low and the second row shows the situation when digital transformation cost is relatively high. As indicated in Figure 13, enterprises with high digital levels tend to possess a greater net income, which is in consistence with conclusions of Figures 4 and 9.

4.3.5. Network Structure. Table 4 shows partial indicators of cooperative innovation network under different environmental policies when $R=60$. The network shows core-periphery structure under both digital transformation costs, but environmental policies have insignificant impacts on network structure. 


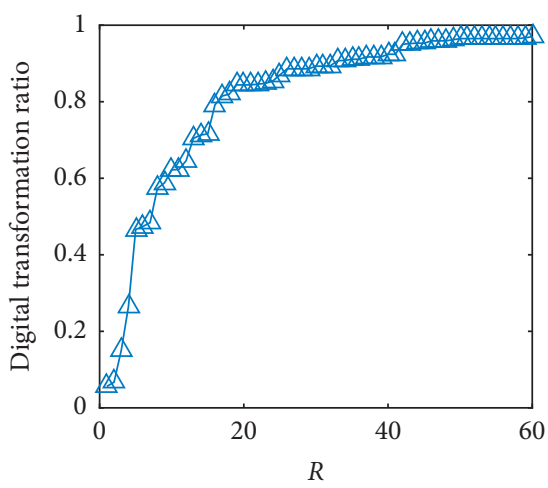

(a)

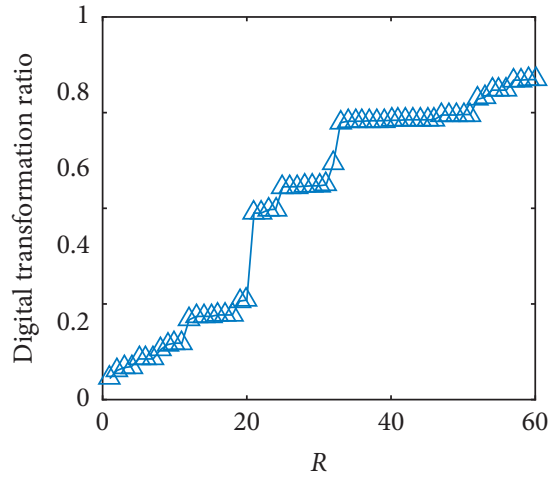

(d)

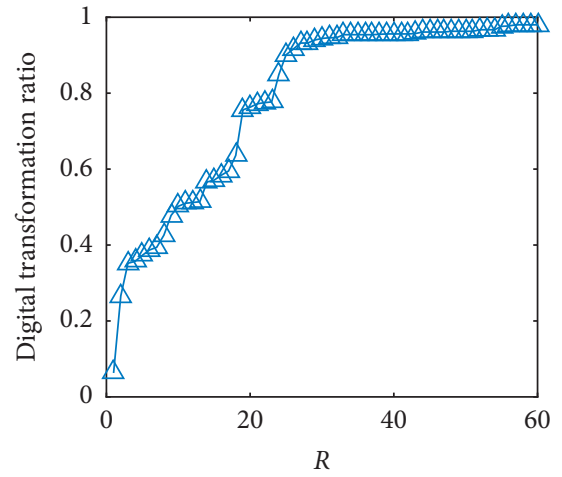

(b)

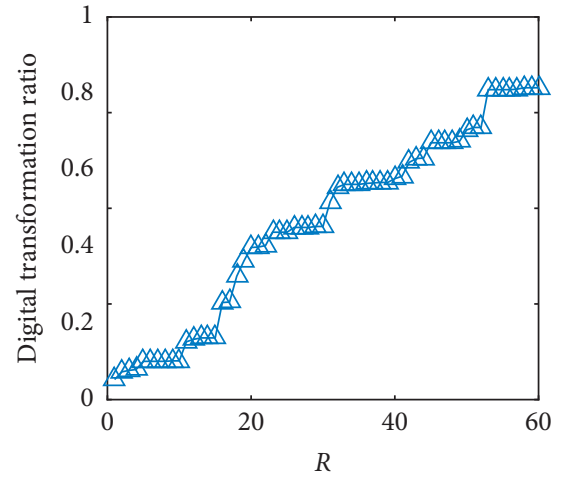

(e)

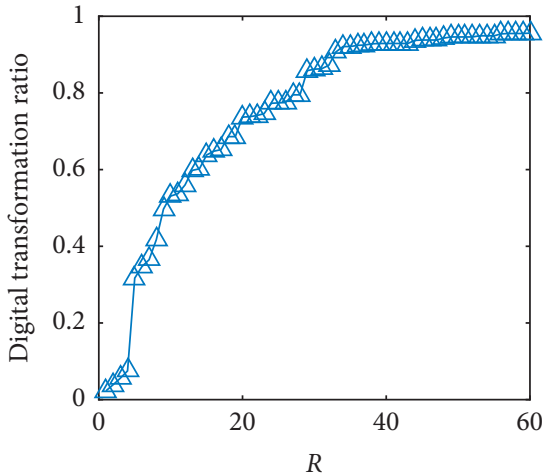

(c)

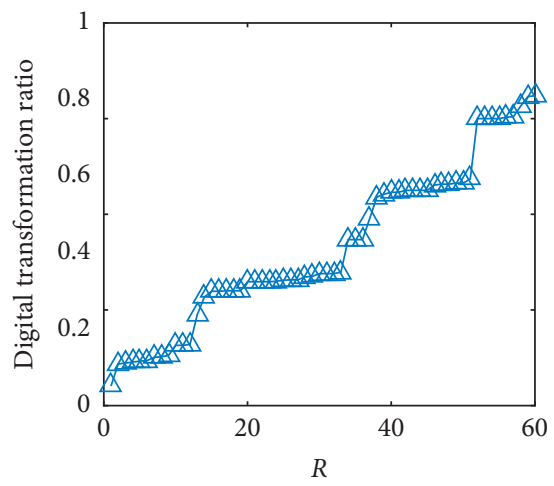

(f)

FIGURE 11: The proportions of enterprises carry out digital transformation under different environmental policies: $(\mathrm{a}) \mathrm{pr}=0.3, \mathrm{Cu}=1, \mathrm{Cb}=2$; (b) $\mathrm{pr}=0.5, \mathrm{Cu}=1, \mathrm{Cb}=2 ;$ (c) $\mathrm{pr}=0.7, \mathrm{Cu}=1, \mathrm{Cb}=2 ;$ (d) $\mathrm{pr}=0.3, \mathrm{Cu}=2, \mathrm{Cb}=4 ;(\mathrm{e}) \mathrm{pr}=0.5, \mathrm{Cu}=2, \mathrm{Cb}=4 ;(\mathrm{f}) \mathrm{pr}=0.7, \mathrm{Cu}=2, \mathrm{Cb}=4$.

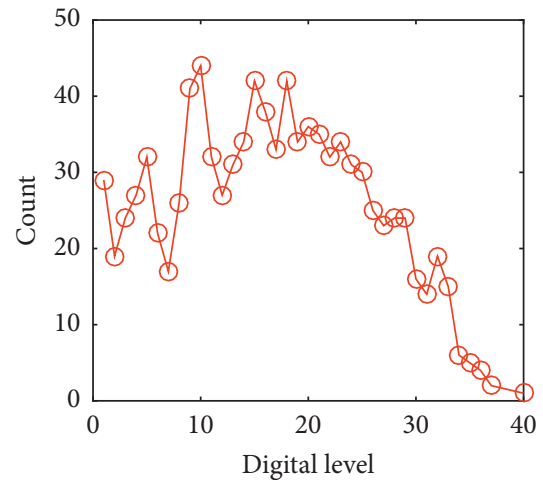

(a)

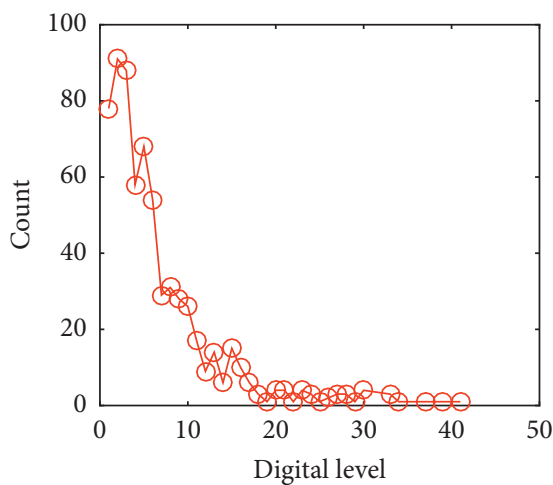

(d)

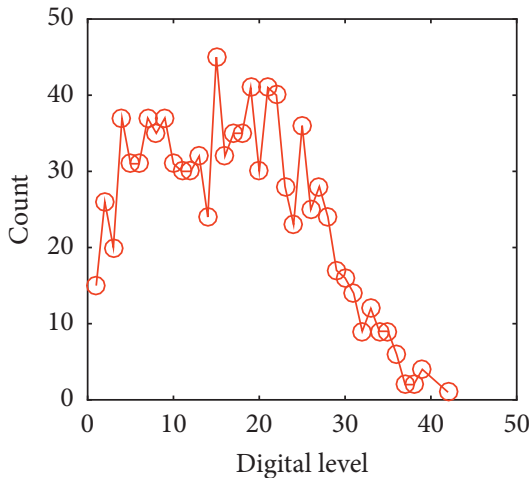

(b)

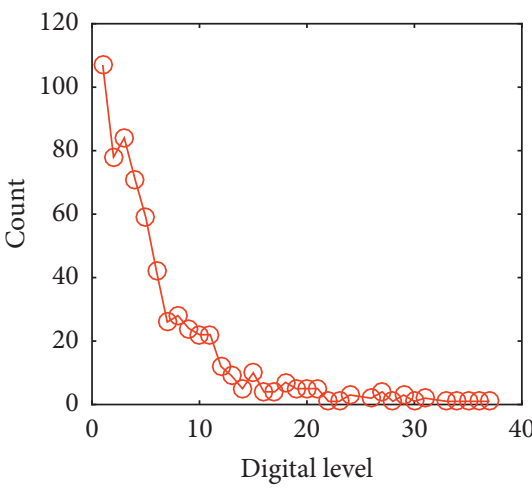

(e)

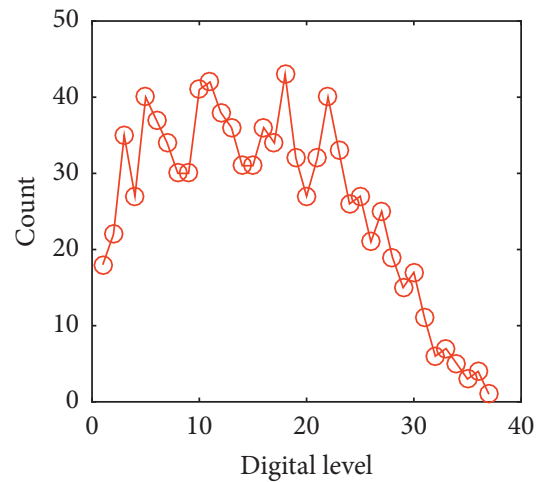

(c)

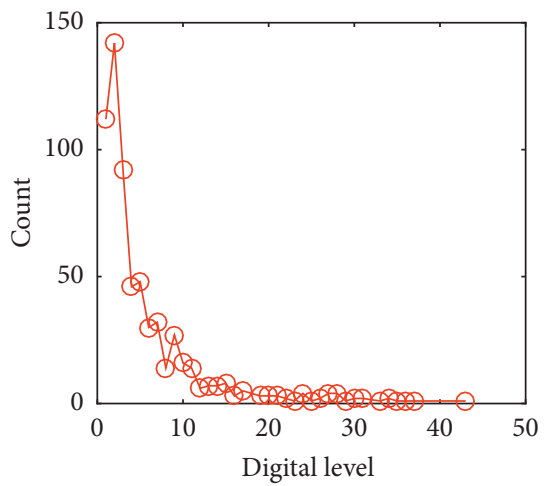

(f)

Figure 12: The digital levels of enterprises under different environmental policies: (a) $\mathrm{pr}=0.3, \mathrm{Cu}=1, \mathrm{Cb}=2 ;(\mathrm{b}) \mathrm{pr}=0.5, \mathrm{Cu}=1, \mathrm{Cb}=2 ;(\mathrm{c})$ $\mathrm{pr}=0.7, \mathrm{Cu}=1, \mathrm{Cb}=2 ;(\mathrm{d}) \mathrm{pr}=0.3, \mathrm{Cu}=2, \mathrm{Cb}=4 ;(\mathrm{e}) \mathrm{pr}=0.5, \mathrm{Cu}=2, \mathrm{Cb}=4 ;(\mathrm{f}) \mathrm{pr}=0.7, \mathrm{Cu}=2, \mathrm{Cb}=4$. 


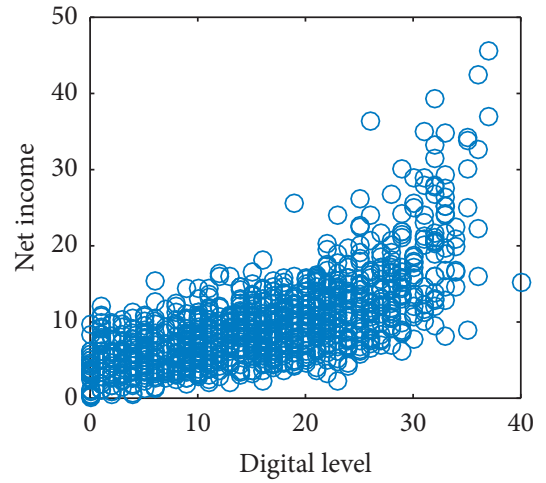

(a)

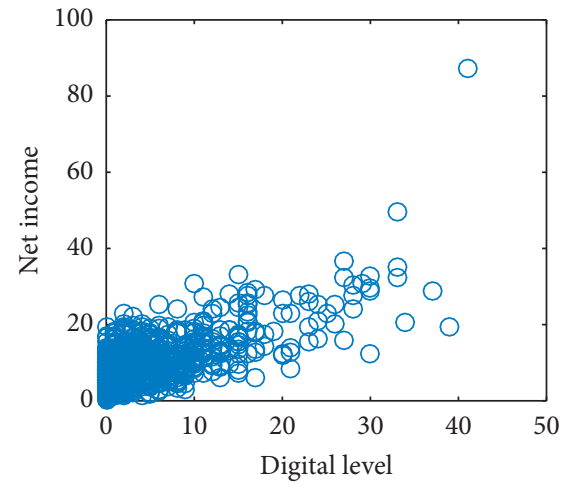

(d)

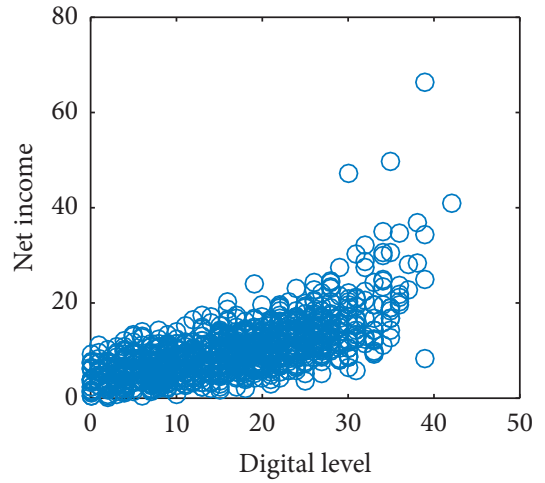

(b)

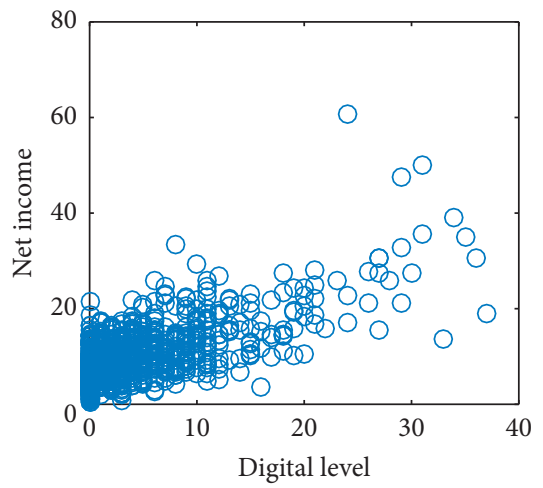

(e)

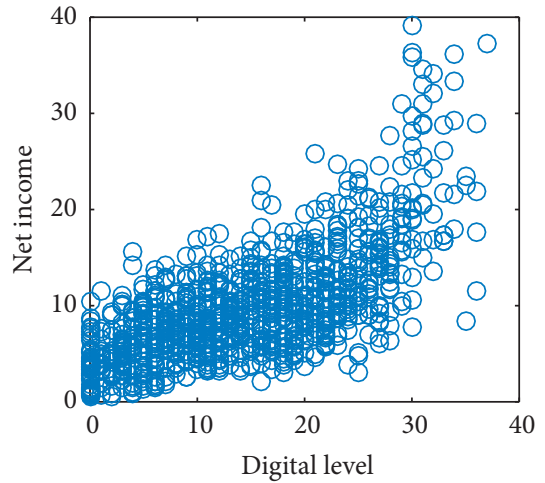

(c)

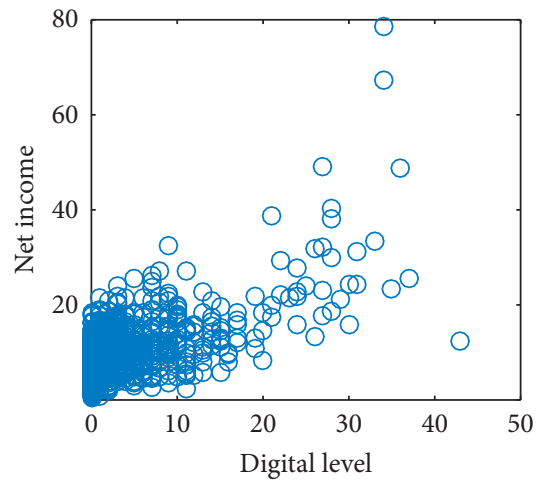

(f)

Figure 13: The digital level of enterprises under different environmental policies when $R=60:(\mathrm{a}) \mathrm{pr}=0.3, \mathrm{Cu}=1, \mathrm{Cb}=2 ;(\mathrm{b}) \mathrm{pr}=0.5$, $\mathrm{Cu}=1, \mathrm{Cb}=2 ;$ (c) $\mathrm{pr}=0.7, \mathrm{Cu}=1, \mathrm{Cb}=2$; (d) $\mathrm{pr}=0.3, \mathrm{Cu}=2, \mathrm{Cb}=4 ;(\mathrm{e}) \mathrm{pr}=0.5, \mathrm{Cu}=2, \mathrm{Cb}=4 ;(\mathrm{f}) \mathrm{pr}=0.7, \mathrm{Cu}=2, \mathrm{Cb}=4$.

TABLE 4: The partial indicators of cooperative innovation network under different environmental policies.

\begin{tabular}{lccccc}
\hline Costs & $N_{I}$ & $A_{C E}$ & $A_{C E \_} S$ & $A_{C}$ & $A_{C \_} S$ \\
\hline$p 1=0.5, \mathrm{pr}=0.3, \mathrm{Cu}=1, \mathrm{Cb}=2$ & 115 & 3.759 & 5 & 5.39 & 8.376 \\
$p 1=0.5, \mathrm{pr}=0.5, \mathrm{Cu}=1, \mathrm{Cb}=2$ & 103 & 3.518 & 4.716 & 5.064 & 8.189 \\
$p 1=0.5, \mathrm{pr}=0.7, \mathrm{Cu}=1, \mathrm{Cb}=2$ & 90 & 3.736 & 4.838 & 5.182 & 7.772 \\
$p 1=0.3, \mathrm{pr}=0.3, \mathrm{Cu}=2, \mathrm{Cb}=4$ & 33 & 3.847 & 4.322 & 4.836 & 5.824 \\
$p 1=0.5, \mathrm{pr}=0.5, \mathrm{Cu}=2, \mathrm{Cb}=4$ & 48 & 3.567 & 4.034 & 4.569 & 5.826 \\
$p 1=0.5, \mathrm{pr}=0.7, \mathrm{Cu}=2, \mathrm{Cb}=4$ & 34 & 3.654 & 4.032 & 4.569 & 5.523 \\
\hline
\end{tabular}

\section{Discussion and Conclusions}

5.1. Main Findings. Facilitation of the digital transformation of innovation ecosystem by means of policies is an important approach to develop the digital economy. This paper builds a multiagent model to study the effects of supply-side policies, demand-side policies, and environmental policies on the digital transformation of innovation ecosystem, and basic conclusions drawn from numerical experiments are as follows.

Firstly, supply-side policies, demand-side policies, and environmental policies all facilitate the digital transformation of innovation ecosystem. From the perspective of effects, the effects of supply-side policies are greater than that of demandside policies, and the effects of environmental policies are the weakest. Secondly, the digital levels of enterprises play an important intermediate and transmission role in the transformation process. On the one hand, enterprises' digital levels show a positive correlation with their net income; the higher the enterprises' digital levels, the more likely for them to occupy a higher market share, and thus the higher the net income. On the other hand, the higher the digital levels of individuals, the more obvious the core-periphery structure in the cooperative innovation network. In other words, there are few enterprises in the system (the core of network), which have long-term stable cooperative relations.

5.2. Theoretical and Policy Implications. This paper is associated with literature in the fields of the innovation ecosystem, digital transformation, and technological policies. Research results have contributions to previous literatures from two aspects. Firstly, this paper carries research on the relationship between policy intervention and innovation ecosystem transformation [8] further. Existing researches pay close attention to the way to get rid of innovation ecosystem transformation failures with technological policies. This paper further focuses on the digital transformation of innovation ecosystem, studies effects of supply-side, demand-side, and environmental policies on digital transformation, and thus carries existing researches further. Secondly, this paper also plays an active role in the development of innovation ecosystem modeling. Theoretical analysis and case study are main research methods of innovation ecosystem at the moment, and application of 
modeling and computational experiments is still obviously inadequate [9], so they fail to effectively depict and represent the complex system characteristics of the innovation ecosystem. The agent-based model built by this paper can help to make up this shortage of research.

This paper also has positive implications for policy practices of digital transformation. First of all, according to the results of this study, policymakers need to choose appropriate policy tools to promote the digital transformation of innovation ecosystem. Specifically, the supply-side policy can effectively break the bottleneck in the transformation process, which should be the first choice of policy tools. Secondly, considering the diminishing marginal effect of policy tools, policymakers should make policy from the perspective of dynamic combination. We should not only consider the process of digital transformation of innovation ecosystem to adjust the policy tools in time but also enlarge the scope of different policy tools to realize the integration and optimization of effects. The concept of tentative governance emerged in recent years enlightens this practice to a huge degree [28]. Third, policymakers need to pay more attention to the microeffect of policy. According to the research of this paper, the digital level of enterprises plays a good intermediary role in the whole process of digital transformation of innovation ecosystem. Therefore, policymakers need to emphasize the role of policy tools in enhancing the digital level of enterprises, especially the leading enterprises which dominate innovation network. Fourth, to enterprises and other innovation agents, digital transformation can help enterprises getting a greater competitive advantage in the innovation ecosystem, occupying core position in the innovation network, and forming relatively stable cooperative relationships with other agents. Therefore, enterprises shall use policy conditions for the implementation of transformation in a more active manner.

\section{Data Availability}

The primary data used to support the findings of this study are available from the author upon request.

\section{Conflicts of Interest}

The authors declare that there are no conflicts of interest regarding the publication of this paper.

\section{Acknowledgments}

This work was supported by the National Natural Science Foundation of China (Grant nos. 71673074 and 71874046), Soft Science Research Program of Zhejiang Province (Grant nos. 2020C25016 and 2019C35055), and Social Science Fund of Zhejiang Province (Grant no. 16JDGH046).

\section{References}

[1] E. D. Adamides and N. Karacapilidis, "Information technology support for the knowledge and social processes of innovation management," Technovation, vol. 26, no. 1 , pp. 50-59, 2006.
[2] L. Z. Song and M. Song, "The role of information technologies in enhancing R\&D-marketing integration: an empirical investigation," Journal of Product Innovation Management, vol. 27, no. 3, pp. 382-401, 2010.

[3] L. Kleis, P. Chwelos, R. V. Ramirez, and I. Cockburn, "Information technology and intangible output: the impact of IT investment on innovation productivity," Information Systems Research, vol. 23, no. 1, pp. 42-59, 2012.

[4] T. Cui, H. Ye, H. H. Teo, and J. Li, "Information technology and open innovation: a strategic alignment perspective," Information \& Management, vol. 52, no. 3, pp. 348-358, 2015.

[5] J. Q. Dong and J. Netten, "Information technology and external search in the open innovation age: new findings from Germany," Technological Forecasting and Social Change, vol. 120, pp. 223-231, 2017.

[6] J. Gómez, I. Salazar, and P. Vargas, "Does information technology improve open innovation performance? An examination of manufacturers in Spain," Information Systems Research, vol. 28, no. 3, pp. 661-675, 2017.

[7] K. M. Weber and H. Rohracher, "Legitimizing research, technology and innovation policies for transformative change," Research Policy, vol. 41, no. 6, pp. 1037-1047, 2012.

[8] R. Raven and B. Walrave, "Overcoming transformational failures through policy mixes in the dynamics of technological innovation systems," Technological Forecasting and Social Change, vol. 153, p. 119297, 2020.

[9] L. A. D. V. Gomes, A. L. F. Facin, M. S. Salerno, and R. K. Ikenami, "Unpacking the innovation ecosystem construct: evolution, gaps and trends," Technological Forecasting and Social Change, vol. 136, pp. 30-48, 2018.

[10] B. Hinings, T. Gegenhuber, and R. Greenwood, "Digital innovation and transformation: an institutional perspective," Information and Organization, vol. 28, no. 1, pp. 52-61, 2018.

[11] M. G. Russell and N. V. Smorodinskaya, "Leveraging complexity for ecosystemic innovation," Technological Forecasting and Social Change, vol. 136, no. 11, pp. 114-131, 2018.

[12] P. T. Roundy, M. Bradshaw, and B. K. Brockman, "The emergence of entrepreneurial ecosystems: a complex adaptive systems approach," Journal of Business Research, vol. 86, pp. 1-10, 2018.

[13] O. Granstrand and M. Holgersson, "Innovation ecosystems: a conceptual review and a new definition," Technovation, vol. 90-91, Article ID 102098, 2020.

[14] M. J. Orlando, "Measuring spillovers from industrial R\&D: on the importance of geographic and technological proximity," The Rand Journal of Economics, vol. 35, no. 4, pp. 777-786, 2004.

[15] Y. Su and Y. Li, "Simulation analysis of knowledge transfer in a knowledge alliance based on a circular surface radiator model," Complexity, vol. 2020, Article ID 4301489, 27 pages, 2020.

[16] L. Aldieri, V. Sena, and C. P. Vinci, "Domestic R\&D spillovers and absorptive capacity: some evidence for US, Europe and Japan," International Journal of Production Economics, vol. 198, pp. 38-49, 2018.

[17] Y. Su and X. An, "Application of threshold regression analysis to study the impact of regional technological innovation level on sustainable development," Renewable and Sustainable Energy Reviews, vol. 89, no. 3, pp. 27-32, 2018.

[18] D. R. Shaw and T. Allen, "Studying innovation ecosystems using ecology theory," Technological Forecasting and Social Change, vol. 136, pp. 88-102, 2018. 
[19] T. Hess, A. Benlian, C. Matt, and F. Wiesböck, "Options for formulating a digital transformation strategy," MIS Quarterly Executive, vol. 15, no. 2, pp. 123-139, 2016.

[20] S. Nambisan, K. Lyytinen, K. Lyytinen, A. Majchrzak, and M. Song, "Digital innovation management: reinventing innovation management research in a digital world," MIS Quarterly, vol. 41, no. 1, pp. 223-238, 2017.

[21] J. Holmström, "Recombination in digital innovation: challenges, opportunities, and the importance of a theoretical framework," Information and Organization, vol. 28, no. 2, pp. 107-110, 2018.

[22] M. De Reuver, C. Sørensen, and R. C. Basole, "The digital platform: a research agenda," Journal of Information Technology, vol. 33, no. 2, pp. 124-135, 2018.

[23] A. Hipp and C. Binz, "Firm survival in complex value chains and global innovation systems: evidence from solar photovoltaics," Research Policy, vol. 49, no. 1, p. 103876, 2020.

[24] S. Lee, H. Lee, and C. Lee, "Open innovation at the national level: towards a global innovation system," Technological Forecasting and Social Change, vol. 151, p. 119842, 2020.

[25] C. Huang, J. Su, X. Xie, and J. Li, "Basic research is overshadowed by applied research in China: a policy perspective," Scientometrics, vol. 99, no. 3, pp. 689-694, 2014.

[26] M. P. Hekkert, R. A. A. Suurs, S. O. Negro, S. Kuhlmann, and R. E. H. M. Smits, "Functions of innovation systems: a new approach for analysing technological change," Technological Forecasting and Social Change, vol. 74, no. 4, pp. 413-432, 2007.

[27] M. Kitsak, L. K. Gallos, S. Havlin et al., "Identification of influential spreaders in complex networks," Nature Physics, vol. 6, no. 11, pp. 888-893, 2010.

[28] S. Kuhlmann, P. Stegmaier, and K. Konrad, "The tentative governance of emerging science and technology-a conceptual introduction," Research Policy, vol. 48, no. 1, pp. 1091-1097, 2019. 